\title{
Poaceae de uma área de floresta montana no sul da Bahia, Brasil: Bambusoideae e Pharoideae ${ }^{1}$
}

\author{
Aline Costa da Mota ${ }^{2}$, Reyjane Patrícia de Oliveira ${ }^{2,3}$ \\ \& Tarciso de Souza Filgueiras ${ }^{4}$
}

\begin{abstract}
Resumo
(Poaceae em uma área de floresta montana no sul da Bahia, Brasil: Bambusoideae e Pharoideae) Foi realizado o levantamento das espécies pertencentes às subfamílias Bambusoideae e Pharoideae (Poaceae) em um remanescente de floresta montana (RPPN Serra Bonita), dentro do bioma Mata Atlântica, situado entre os municípios de Camacan e Pau Brasil, na microrregião Litoral Sul da Bahia. Bambusoideae está representada na área de estudos por seis gêneros e nove espécies, e Pharoideae, apenas por Pharus lappulaceus Aubl. Em Bambusoideae, Chusquea Kunth foi o gênero que apresentou maior número de espécies (quatro spp.), enquanto os demais gêneros estão representados por uma espécie cada. Dentre os materiais coletados, apenas dois não foram satisfatoriamente identificados, pois não se enquandraram em nenhuma das descrições conhecidas dos seus respectivos gêneros (Chusquea sp. e Diandrolyra sp.). São aqui apresentadas chaves de identificação para subfamílias, gêneros e espécies, além de descrições, ilustrações e comentários.
\end{abstract}

Palavras-chave: gramíneas, Pharoideae, Bambusoideae, floresta montana, Bahia.

\section{Abstract}

(Poaceae in a montane forest in the Southeastern Bahia, Brazil: Bambusoideae and Pharoideae) This study is a survey of Bambusoideae and Pharoideae (Poaceae) in a remnant of montane forest (RPPN Serra Bonita), in the Brazilian Atlantic Forest, between Camacan and Pau Brasil, southeastern coast of Bahia State. Bambusoideae is represented in the area by six genera and nine species, and Pharoideae only for Pharus lappulaceus Aubl. In Bambusoideae, Chusquea Kunth was the largest genus (four spp.), whereas the remaining genera are represented by a single species each. Only two materials were not satisfactorily identified, because they didn't fit with any description of known species in theirs genera (Chusquea sp. and Diandrolyra sp.). Identification key for subfamilies, genera and species, besides descriptions, illustrations and commentaries are provided.

Key words: grasses, Pharoideae, Bambusoideae, montane forest, Bahia.

\section{INTRODUÇÃO}

Poaceae encontra-se atualmente subdividida em 13 subfamílias (GPWG 2001; Sanchéz-Ken et al. 2007), das quais apenas Puelioideae não ocorre no Brasil. É uma das mais diversificadas famílias de angiospermas, incluindo aproximadamente 700 gêneros e 10.000 espécies (GPWG 2001). Destas, cerca de 1.368 espécies, distribuídas em 200 gêneros, foram citadas para o país por Burman (1985), porém este número vem aumentando consideravelmente com a publicação de novos gêneros e espécies.
No nordeste do Brasil, poucos estudos focaram as espécies de Poaceae até o momento. A obra mais importante foi publicada por Renvoize (1984), onde foram descritas e ilustradas cerca de 300 espécies ocorrentes na Bahia. Outros levantamentos foram realizados em áreas mais pontuais deste estado, especialmente na Chapada Diamantina, como Harley \& Simmons (1986) para a região de Mucugê (34 spp.); Renvoize (1995), para o Pico das Almas (38 spp.); Menezes \& Pinto (1998), para a Serra da Chapadinha e Morro do Pai Inácio (dez spp.); e Renvoize (2003),

Artigo recebido em 02/2009. Aceito para publicação em 11/2009.

${ }^{1}$ Parte da dissertação de Mestrado da primeira autora.

${ }^{2}$ Universidade Estadual de Feira de Santana, Depto. Ciências Biológicas, Programa de Pós-Graduação em Botânica, Av. Transnordestina s/n, 44036-460, Feira de Santana, BA, Brasil. Autor para correspondência: alinecostamota@gmail.com ${ }^{3}$ Universidade Federal da Bahia, Depto. Botânica, Av. Ademar de Barros s.n., Campus de Ondina, 40170-150, Salvador, BA, Brasil.

${ }^{4}$ Reserva Ecológica do IBGE, C. Postal 08770, 70312-970, Brasília, DF, Brasil. 
para a região de Catolés, município de Abaíra (48 spp.).

Embora esses levantamentos tenham sido desenvolvidos predominantemente em campos rupestres e cerrados, eventualmente citaram espécies de Poaceae ocorrentes em áreas florestais. Especificamente para florestas interioranas, existem apenas os levantamentos de Carvalho-Sobrinho \& Queiroz (2005), para a Serra da Jibóia (nove ssp.) e Cardoso \& Queiroz (2008), para a Serra do Orobó (oito ssp.). Poaceae é um grupo bastante representativo ao longo da floresta atlântica, sendo essa considerada como um grande centro de diversidade de bambus (Soderstrom et al. 1988), cujas espécies são representantes da subfamília Bambusoideae (e.g., Merostachys Spreng., Chusquea Kunth, Olyra L. e Pariana Aubl.).

Os inventários já realizados nesta região que incluíram representantes de Poaceae, abordaram especialmente as áreas com baixas altitudes, como a Reserva Biológica de Una e Serra Grande (Thomas et al. 1998), e Serra do Teimoso (Amorim et al. 2005), não existindo, até o momento, nenhum levantamento que envolva as espécies de Poaceae ocorrentes nas florestas montanas.

A região sul da Bahia se destaca quanto à alta riqueza biológica e alto grau de endemismos locais. Por outro lado, vem sofrendo forte pressão através de contínuos desmatamentos, o que pode ser comprovado pela redução da cobertura florestal no extremo sul do estado, de 85,36\% em 1945 para 6,04\% em 1990 (Mendonça et al. 1994). Trata-se de uma das áreas com vegetação mais afetada, inicialmente alterada para o cultivo de cacau e hoje composta, em sua maioria, por pastagens ou monoculturas, como o eucalipto. Alguns fragmentos foram preservados em função do baixo potencial agrícola, principalmente as áreas dos topos das montanhas, mas são poucas as áreas oficialmente protegidas.

Portanto, este trabalho teve como objetivo realizar o levantamento das subfamílias Bambusoideae e Pharoideae (Poaceae) em um remanescente de floresta atlântica montana, a fim de contribuir para o conhecimento da família nas florestas da Bahia e fornecer subsídios que avaliem a necessidade de manutenção desses remanescentes e de outros similares.

\section{Material e Métodos}

O presente levantamento foi realizado na área de floresta atlântica montana da Reserva Particular do Patrimônio Natural (RPPN) Serra Bonita (coordenadas geográficas da sede: $15^{\circ} 23^{\prime} 30^{\prime \prime} \mathrm{S}$ e $39^{\circ} 33^{\prime} 55^{\prime \prime} \mathrm{W}$ ), a qual foi criada pelas portarias do IBAMA $\mathrm{n}^{\circ} 15$ de $04 /$ 03/04, n' 16 de 04/03/04, no 33 de 09/03/04 e n ${ }^{\circ}$ 36 de 09/03/04 (IBAMA 2004) e possui 1.200 hectares incluindo florestas submontana e montana. A propriedade situa-se na microrregião Litoral Sul da Bahia, com maior parte no município de Camacan e uma parte menor no município de Pau Brasil (Fig. 1). Camacan apresenta clima úmido a subúmido, com relevo de serras e maciços pré-litorâneos e tabuleiro do Rio Pardo, enquanto Pau Brasil possui clima úmido, subúmido a seco, com relevo constituído pela depressão de Itabuna-Itapetinga e tabuleiro do Rio Pardo (SEI 2007). Com uma área total de 7.500 hectares, com fortes gradientes altitudinais (entre 180 e $940 \mathrm{~m}$ acima do nível do mar), a Serra Bonita apresenta 50\% de sua área coberta por floresta primária, e o restante apresenta áreas modificadas, com florestas secundárias em diversos estádios de regeneração e áreas de cabruca (sistema de cultivo de cacau).

Foram realizadas nove expedições para essa área de estudo, entre maio/2007 e abril/ 2008. As coletas ocorreram ao longo das cinco trilhas principais, com extensão média de $1 \mathrm{~km}$ cada; e também nas secundárias com menores extensões que partem das principais. Estas trilhas percorrem no geral toda a extensão da floresta montana da RPPN, e a partir destas trilhas foram feitas coletas aleatórias saindo das principais, com intuito de abranger todas as fisionomias e microambientes. Os microambientes amostrados incluiram o interior da floresta, as clareiras e bordas da floresta e em áreas alteradas no entorno da floresta, 

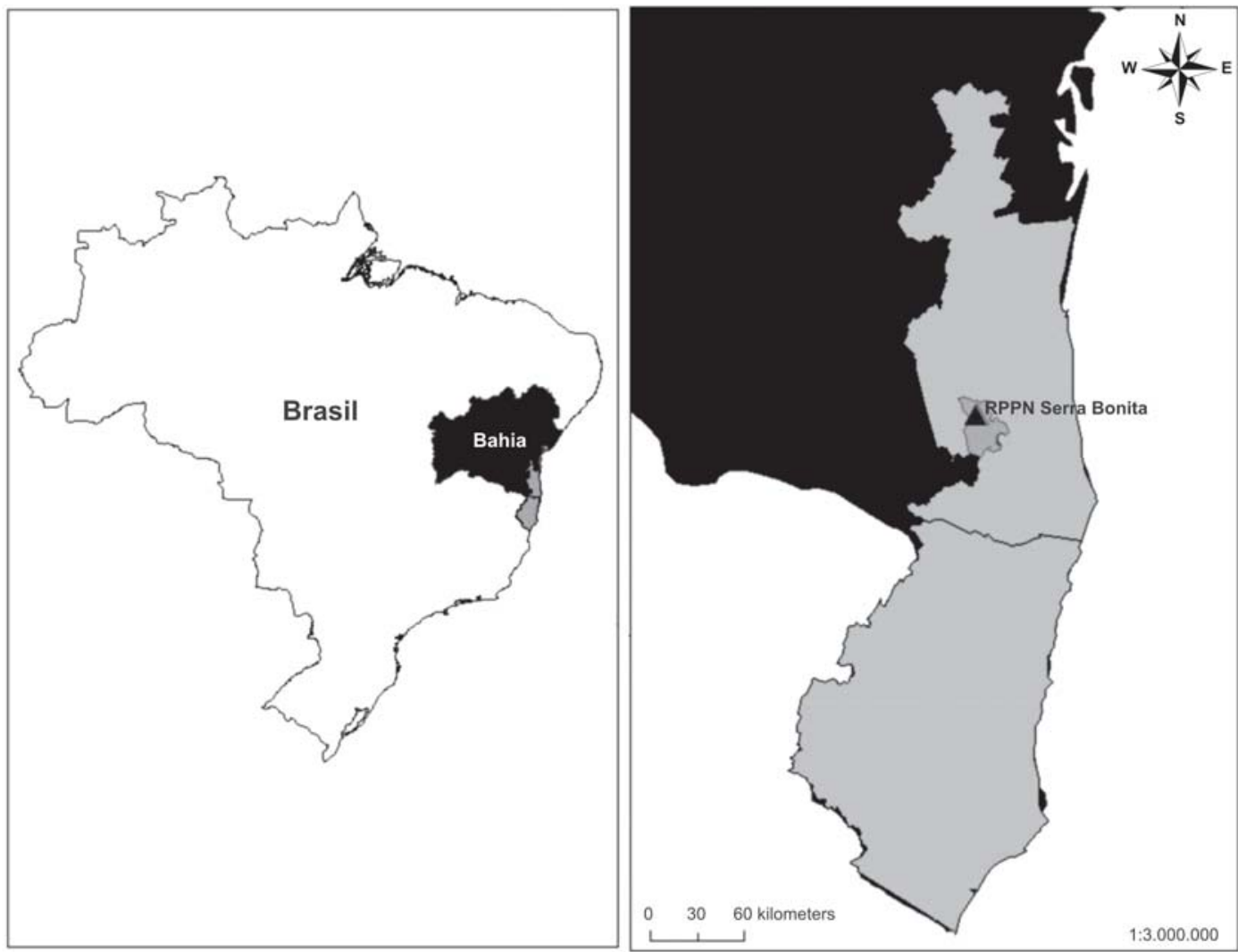

Figura 1 - Mapa de localização da área de estudo (RPPN Serra Bonita).

Figure 1 - Location of the area (RPPN Serra Bonita).

incluindo riachos, mirantes e áreas rochosas. Todos os materiais foram fotografados em campo e foram feitas observações relacionadas às condições ecológicas.

O trabalho de campo seguiu os procedimentos habituais, envolvendo coleta, prensagem, secagem e confecções de exsicatas (Mori et al. 1989). No caso dos bambus, procurou-se atender às sugestões propostas por Soderstrom \& Young (1983). As coleções foram depositadas no herbário HUEFS, e as duplicatas foram enviadas especialmente ao CEPEC, NY, RB, SP e ICN (siglas segundo Holmgren \& Holmgren 2007).

Foram ainda analisados materiais depositados nos principais herbários com coleções representativas de materiais provenientes de coletas na floresta atlântica da Bahia: ALCB, CEPEC, HRB, HUEFS, RB, SP e SPF. Todos os materiais foram identificados com o auxílio de bibliografia especializada, tendo como ponto de partida o trabalho de Renvoize (1984). Os espécimes foram analisados através dos métodos tradicionais em taxonomia, sendo descritos e ilustrados principalmente os caracteres diagnósticos. A distribuição geográfica das espécies foi baseada nos dados disponíveis da literatura e nas etiquetas de herbário dos espécimes examinados.

\section{Resultados e Discussão}

Na floresta montana da RPPN Serra Bonita foram encontradas nove espécies pertencentes a subfamília Bambusoideae e uma espécie pertencente a Pharoideae. Os representantes destas subfamílias foram coletados exclusivamente no interior da floresta, com exceção de Olyra latifolia L. e Parodiolyra micrantha (Kunth) Davidse \& Zuloaga, que ocorrem também nas bordas da floresta. 


\section{Chave para subfamílias de Poaceae ocorrentes na floresta montana da Serra Bonita}

1. Plantas lignificadas, monocárpicas e plurianuais, com espiguetas bissexuadas ou herbáceas a sublignificadas, pluricárpicas e perenes, ou monocárpicas anuais; folhas com pseudopecíolo desenvolvido (porção estreitada e endurecida entre a lâmina e a bainha sem expansão lateral da lâmina).

2. Lâminas foliares sem torção de $180^{\circ}$ no pseudopecíolo; espiguetas bissexuais ou unissexuais, glabras ou com tricomas simples, não aderentes 1. Bambusoideae

2'. Lâminas foliares com uma torção de $180^{\circ}$ no pseudopecíolo; espiguetas femininas com tricomas uncinados, aderentes 2. Pharoideae

1'. Plantas herbáceas com espiguetas bissexuais (pelo menos em um antécio da espigueta); folhas sem pseudopecíolo (apresentando ou não um leve estreitamento em direção à base, ou seja, uma porção estreitada e endurecida entre a lâmina e a bainha com expansão lateral da lâmina).

3. Espiguetas bifloras, acrótonas, o antécio superior bissexual e o inferior masculino ou neutro; glumas caducas com os antécios maduros .... 3. Panicoideae

3'. Espiguetas 1-plurifloras, basítonas, com ou sem antécios neutros apicais rudimentares; glumas persistentes após a queda dos antécios..... 4. Chloridoideae

\section{Bambusoideae}

Bambusoideae é composta pelas tribos Olyreae (bambus herbáceos) e Bambuseae (bambus lignificados), incluindo 60 a 70 gêneros e ca. 1.200 espécies (Zhang \& Clark 2000; GPWG 2001; Oliveira 2006). Apresenta ampla distribuição e ocorre desde o nível do mar até cerca de $4.000 \mathrm{~m}$ de altitude (Soderstrom \& Calderón 1974; Soderstrom et al. 1988). A maior diversidade e endemismo do grupo na região neotropical concentra-se no Brasil (34 gêneros e ca. 230 espécies) (Filgueiras \& Santos-Gonçalves 2004), em especial nas florestas costeiras da Bahia (Clark 1990; Judziewicz et al. 1999).

Na Serra Bonita, foram encontrados representantes das duas tribos, sendo três gêneros e seis espécies pertencentes a Bambuseae, e três gêneros e três espécies a Olyreae.

\section{Chave para os gêneros de Bambusoideae}

1. Plantas lignificadas, acima de $5 \mathrm{~m}$ de altura, muito ramificadas; espiguetas bissexuais.

2. Colmos com entrenós geralmente sólidos ou semi-fistulosos em alguma fase do desenvolvimento, cavidade central não definida .. 1. Chusquea

2'. Colmos com entrenós totalmente fistulosos, cavidade central bem definida.

3. Ramos espinescentes, sendo um deles dominante em cada nó; lâminas das folhas dos ramos de coloração uniforme na face abaxial, sem uma faixa verde-escura marginal

2. Guadua

3'. Ramos não espinescentes, sem um ramo dominante em cada nó; lâminas das folhas dos ramos apresentando na face abaxial uma faixa verde-escura marginal

3. Merostachys

1'. Plantas herbáceas ou sublignificadas, até $2 \mathrm{~m}$ de altura, raramente ramificadas; espiguetas unissexuais.

4. Plantas sublignificadas, robustas, 1-2 m altura; inflorescências paniculadas; estames 3 .

5. Espiguetas femininas desarticulando-se acima das glumas, com pedicelos espessados no ápice e antécios lisos 4. Olyra

5'. Espiguetas femininas desarticulando-se abaixo das glumas, com pedicelos filiformes e antécios foveolados

4'. Plantas herbáceas, delicadas, menores que $50 \mathrm{~cm}$ altura; inflorescências racemosas; estames 2 
1. Chusquea Kunth, J. Phys. Chim. Hist. Nat. Arts 95: 151. 1822.

O colmo sólido é muito característico de Chusquea, com exceções conhecidas apenas para duas espécies extrabrasileiras (do México e Colômbia), as quais apresentam uma cavidade central bem definida (Clark 2001). Outro carater diagnóstico é a presença de gemas múltiplas em cada nó, que origina ramos semelhantes e apenas um deles dominante e com diâmetro muito maior que os demais, além da ausência de fimbrias apicais nas bainhas dos colmos e dos ramos.

Chusquea compreende 130 espécies descritas e uma estimativa de mais de 70 espécies novas (Clark 1996). É exclusivamente americano e largamente distribuído do México até Argentina e Chile (Clark 1995). Ocorre desde o nível do mar até $4.000 \mathrm{~m}$ de altitude, com espécies características de campos de altitude, mas a maioria ocorre em florestas montanas, sendo bem representativas também em planícies tropicais, vegetação litorânea, florestas de galeria, de araucárias e de pinheiros (Clark 1997).

No Brasil ocorrem mais de 50 espécies, e destas, apenas cinco foram referidas para a Bahia (Clark 2001). Na Serra Bonita, foram identificadas quatro espécies: C. bradei L.G. Clark, C. bambusoides (Raddi) Hack. e $C$. oxylepis (Hack.) Ekman, e um material que não se enquadra em nenhuma das espécies conhecidas, aqui tratado como Chusquea sp.

\section{Chave para as espécies de Chusquea}

1. Colmos sempre sólidos, os mais jovens sem faixa de cera branca abaixo dos nós, entrenós com coloração verde uniforme; gema principal patente; lâminas das folhas dos ramos totalmente verdes.

2. Folhas dos colmos com bainhas escabras ou esparsamente pilosas; ramos com nós intumescidos; folhas dos ramos com bainhas glabras a pubescentes apenas no ápice ou escabras, lígula interna maior que $2 \mathrm{~mm}$ compr., lâminas com mais de 10 nervuras secundárias; pseudopecíolo glabro; inflorescências em panículas típicas, abertas ou pouco congestas, não subtendidas por brácteas espatiformes.

3. Folhas dos ramos com bainhas glabras e às vezes pubescentes no ápice; lâminas cartáceas, glabras em ambas as faces; bainhas das folhas dos ramos sem extensão apical, margens escabras apenas no ápice 1.1 C. bambusoides

3'. Folhas dos ramos com bainhas escabras; lâminas membranáceas, escabras próximo à base na face adaxial e com tricomas concentrados na base, na face abaxial; bainhas das folhas dos ramos com extensão apical, margens fortemente ciliadas

1.2 C. oxylepis

2'. Folhas dos colmos com bainhas hirsutas; ramos com nós não intumescidos; folhas dos ramos com bainhas pilosas, lígula interna ca. $1 \mathrm{~mm}$ compr., lâminas com 4-7 nervuras secundárias; pseudopecíolo piloso; inflorescências em panículas capitadas, fortemente congestas, subtentidas por brácteas espatiformes.... 1.3 C. bradei

1'. Colmos sólidos a semi-fistulosos, os mais jovens com faixa de cera branca abaixo dos nós, entrenós com manchas castanhas a vináceas; gema principal ascendente; lâminas das folhas dos ramos esverdeadas com manchas vináceas 1.4 Chusquea sp.

1.1 Chusquea bambusoides (Raddi) Hack., Ergebn. Bot. Exp. Sudbras. 1: 20. 1906.

Fig. 2a-h, 3a-b

Plantas perenes, lignificadas, escandentes, rizomas paquimorfos; colmos ca. $10 \mathrm{~m}$ alt., $3-$ $8 \mathrm{~mm}$ diâm., sem uma faixa de cera branca abaixo dos nós; entrenós ca. 30,5cm compr., sólidos, com medula muito densa, esverdeados, escabros, nós glabros; ramificação infravaginal, gema principal patente, perpendicular ao colmo, 4-8 ramos, (10-14)19-41(46) cm compr., 11,8 mm diâm., nós intumescidos. Folhas dos colmos com bainhas decíduas, escabras, margens glabras; lâminas ca. $7 \times 1,5 \mathrm{~cm}$, triangulares, 
eretas, decíduas, face adaxial denso-escabra, face abaxial escabra, margens escabras; lígula interna membranoso-ciliada, ca. 0,5 mm compr. Folhas dos ramos 3-10, bainhas glabras, às vezes pubescentes no ápice, margens glabras, sem extensões apicais; lígula externa formando um colar ca. $1 \mathrm{~mm}$ compr., lígula interna membranoso-ciliada, ca. 2,5 $\mathrm{mm}$ compr., pubescente; pseudopecíolo 2-3(5) mm compr., glabro em ambas as faces; lâminas (4-)7,5$17,4(-25,5) \times 1,5-2,6(3,6) \mathrm{cm}$, oval-lanceoladas a lanceoladas, cartáceas, ápice agudo a acuminado, base arredondada, assimétrica, glabra em ambas as faces, margens escabras apenas no ápice, esverdeadas, sem manchas vináceas. Inflorescências em panículas típicas, abertas ou pouco congestas, não subtendidas por brácteas espatiformes, 3,5-8,5 × 1-4 cm, pedúnculos 1-8 compr., glabros, ráquis glabra, pedicelos glabros. Espiguetas 7-8 $\times 3-3,5 \mathrm{~mm}$, glumas menores que a espigueta; gluma I 1-2 $\times 1 \mathrm{~mm}$, oval, aristada, arista 1-2 mm compr., escabra no ápice, margens glabras, 5-nervada; gluma II 1-2 $\times 1 \mathrm{~mm}$, oval, aristada, arista 1$2 \mathrm{~mm}$ compr., escabra no ápice, margens glabras, 5-nervada; gluma III 4-5 $\times 2 \mathrm{~mm}$, oval, apiculada, esparsamente escabra, margens glabras, 7-nervada; gluma IV 5-6×2 mm, oval, apiculada, esparsamente escabra, margens glabras, 7-nervada; lema 6-7 × $3 \mathrm{~mm}$, lanceolado, agudo, escabro, margens glabras, 9-nervado; pálea 6-6,5 × $3 \mathrm{~mm}$, lanceolada, aguda, escabra, margens glabras, 8-nervada. Frutos não vistos.

Material selecionado: trilha da torre, 30.VI.2007, fl., A.C. Mota 70 (HUEFS); trilha nova, 26.VIII.2007, fl., F.M. Ferreira et al. 1306 (CEPEC); trilha da pousada, 24.XI.2007, fl., A.C. Mota 188 (HUEFS); trilha da bapeba, 28.II.2008, fl., A.C. Mota 223 (HUEFS).

Os materiais de Chusquea bambusoides coletados na Serra Bonita possuem ampla variação morfológica, mas a maioria dos caracteres concorda com as descrições dessa espécie encontradas na literatura (e.g., Renvoize 1984; Clark 2001). Diferenças na variação morfológica foram observadas na pilosidade dos colmos (escabros versus lisos) e no comprimento da gluma IV e lema, um pouco menores em alguns materiais (ca. 5 e $7 \mathrm{~mm}$ compr. versus 6-8 $\mathrm{mm}$ e $8-10 \mathrm{~mm}$ compr., respectivamente). Estas diferenças foram aqui aceitas como variações morfológicas dentro dos limites da espécie.

$\mathrm{Na}$ área de estudos, pode ser confundida com Chusquea oxylepis, possuindo o mesmo hábito e porte, além de compartilharem igual número de ramos e nós intumescidos. Porém, é possível diferenciá-las principalmente por caracteres vegetativos, pois $C$. bambusoides apresenta folhas dos ramos totalmente glabras na face abaxial, enquanto $C$. oxylepis apresenta tricomas concentrados na base da lâmina.

Chusquea bambusoides ocorre no leste do Brasil, em floresta ombrófila de 3 a $500 \mathrm{~m}$ de altitude (Renvoize 1984). Pelo grande número de indivíduos coletados em floração e encontrados em herbário, supõe-se tratar de uma espécie que floresce frequentemente, provavelmente com ciclos de poucos anos para uma mesma população. Até agora nenhuma floração gregária foi documentada (Clark 2001). Na Serra Bonita ocorre exclusivamente no interior da floresta, entre 500 e $940 \mathrm{~m}$ de altitude, sob baixa intensidade luminosa e esteve florida durante todo o período de coleta. É a espécie de bambu mais numerosa e amplamente distribuida na área de estudo, sendo normalmente observados indivíduos em vários estágios de crescimento. Segundo observações de moradores locais, em alguns períodos durante a floração dessa espécie, é intensa a visita de insetos, especialmente de abelhas.

1.2 Chusquea oxylepis (Hack.) Ekman, Art. Bot. 13(10): 65. $1913 . \quad$ Fig. 2i-m, 3c-d Plantas perenes, lignificadas, escandentes, rizomas paquimorfos; colmos ca. $10 \mathrm{~m}$ alt., 5$7 \mathrm{~mm}$ diâm., sem uma faixa de cera branca abaixo dos nós; entrenós 27-29 cm compr., sólidos, com medula densa, esverdeados, hirsutos, nós glabros; ramificação infravaginal, gema principal patente, perpendicular ao colmo, 5-6 ramos, 24-48 cm compr., 1,5-2 diâm., nós intumescidos. Folhas dos colmos com bainhas 


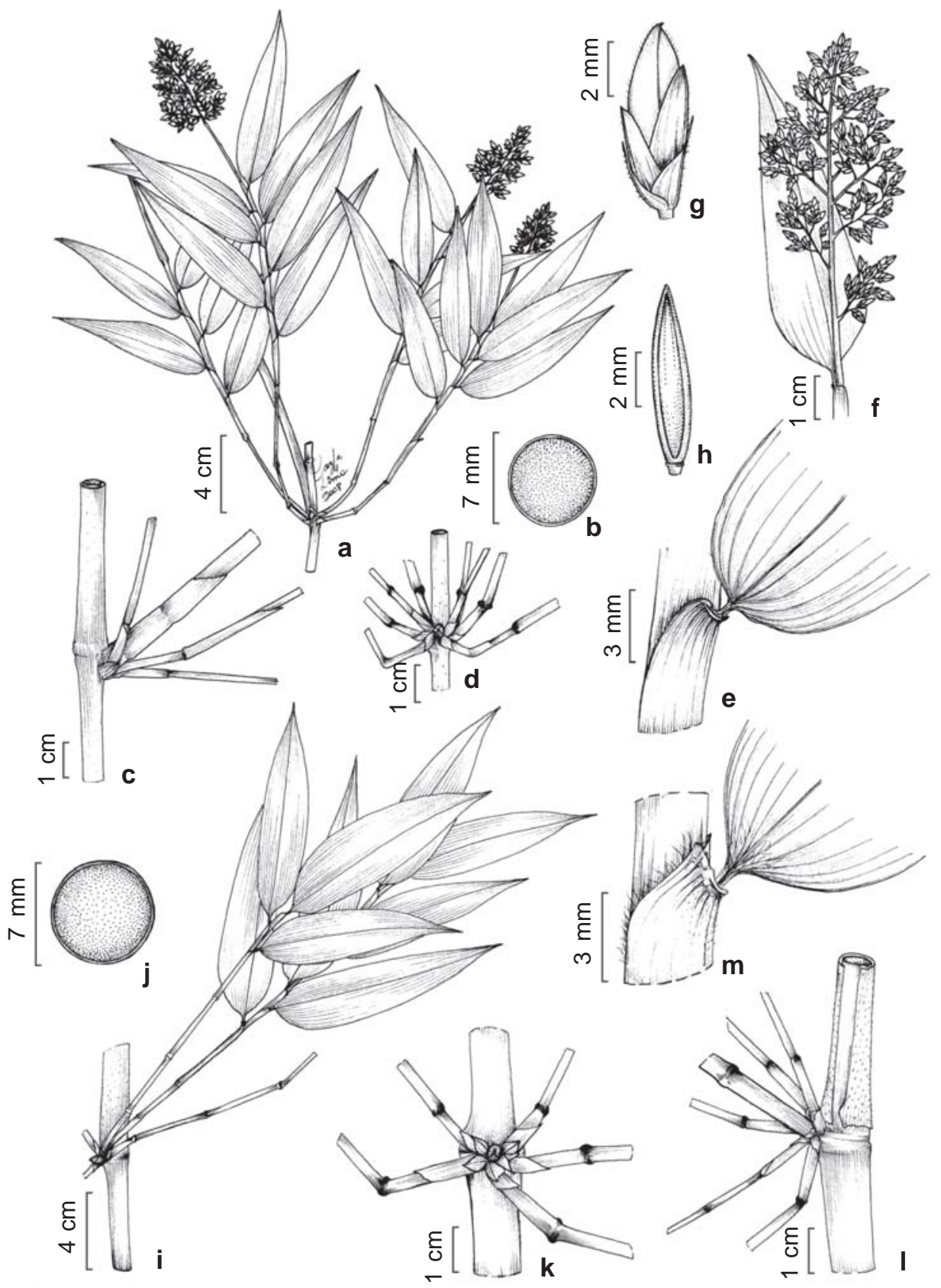

Figura 2 - a-h. Chusquea bambusoides - a. ramos com folhas e inflorescências; b. corte transversal do colmo; c. vista lateral da ramificação; d. vista frontal da ramificação, mostrando gema principal patente; e. detalhe da bainha da folha do ramo, pseudopecíolo e base da lâmina. f. Inflorescência; g. espigueta; h. antécio, vista da pálea. i-m. Chusquea oxylepis - i. ramos com folhas; j. corte transversal do colmo; $\mathrm{k}$. vista frontal da ramificação, mostrando gema principal patente; 1 . vista lateral da ramificação, mostrando ramo principal desenvolvido; $m$. detalhe da bainha da folha do ramo (evidenciando a extensão apical), pseudopecíolo e base da lâmina. (a-e A.C. Mota 188 (HUEFS); f-h A.C. Mota 223 (HUEFS); i-m A.C. Mota 195 (HUEFS)).

Figure 2 - a-h. Chusquea bambusoides - a. branch with leaves and inflorescences; b. culm, transversal view; c. branching, lateral view; d. branching, frontal view, showing patent main bud; e. details of the sheath branch, pseudopetiole and base of the blade; f. inflorescence; g. spikelet; h. anthecium, palea view. i-m. Chusquea oxylepis - i. branches with leaves; j. culm, traversal view; k. branching, frontal view, showing patent main bud; 1. branching, lateral view, showing developed main branch; m. detail of the sheath branch (evidencing the apical extension), pseudopetiole and base of the blade. (a-e A.C. Mota 188 (HUEFS); fh A.C. Mota 223 (HUEFS); i-m A.C. Mota 195 (HUEFS)). 

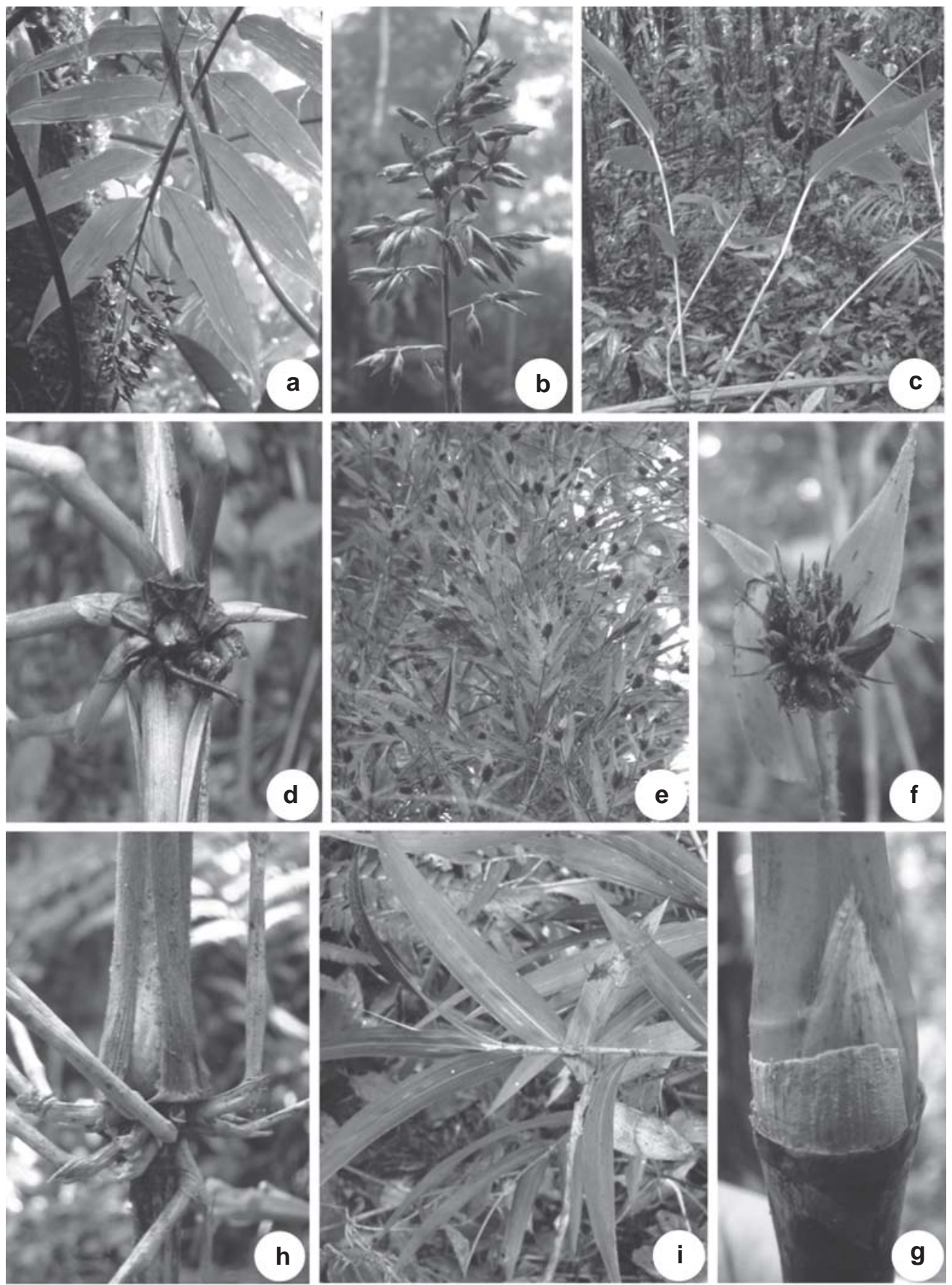

Figura 3 - a-b. Chusquea bambusoides - a. folhas do ramos e inflorescência; b. inflorescência. c-d. Chusquea oxylepis c. folhas dos ramos; d. detalhe da ramificação e gema central. e-f. Chusquea bradei - e. folhas dos ramos e inflorescências; f. inflorescência. g-i. Chusquea sp. - g. detalhe da gema ascendente e faixa de cera branca abaixo do nó; h. detalhe da ramificação; i. detalhe das folhas dos ramos com manchas. (a A.C. Mota 223 (HUEFS); b A.C. Mota 188 (HUEFS); c-d A.C. Mota 195 (HUEFS); e-f A.C. Mota 222 (HUEFS); g-i A.C. Mota 258 (HUEFS)).

Figure 3 - a-b. Chusquea bambusoides - a. leaves and inflorescence branches; b. inflorescence. c-d. Chusquea oxylepis - c. branch leaves; d. details of branching and main bud. e-f. Chusquea bradei - e. branch leaves and inflorescences; f. inflorescence. g-i. Chusquea sp. - g. details of the ascending bud and white band below the node; h. detail of the branching; i. detail of branch leaves with spots. (a A.C. Mota 223 (HUEFS); b A.C. Mota 188 (HUEFS); c-d A.C. Mota 195 (HUEFS); e-f A.C. Mota 222 (HUEFS); g-i A.C. Mota 258 (HUEFS)). 
decíduas, escabras e pubescentes, margens fortemente ciliadas, cílios ca. $1 \mathrm{~mm}$ compr.; lâminas 6,6-8×0,4-0,5 cm, estreito-triangulares, eretas, decíduas, escabra em ambas as faces e margens; lígula interna membranoso-ciliada, ca. 0,5 cm compr. Folhas dos ramos 3-6, bainhas escabras, margens ciliadas, cílios 1-2 mm compr., com extensões apicais ca. $1 \mathrm{~mm}$ compr.; lígula externa formando colar ca. $1 \mathrm{~mm}$ compr., lígula interna membranoso-ciliada, 2-3 mm compr., escabras; pseudopecíolo 2-5 mm compr., glabro em ambas as faces; lâminas 8-17,7 × 1,9-3,6 $\mathrm{cm}$, oval-lanceoladas, membranáceas, ápice acuminado, base arredondada, assimétrica, face adaxial escabra próximo à base, face abaxial pilosa próximo à base, margens fortemente ciliadas, esverdeadas, sem manchas vináceas. Inflorescências não vistas.

Material selecionado: trilha da pousada, 26.V.2007, A. C. Mota et al. 53 (CEPEC); trilha da casa de Vitor para a pousada, 28.II.2008, A. C. Mota 221 (HUEFS).

Chusquea oxylepis apresenta morfologia marcante entre as espécies que ocorrem na Serra Bonita. Possui caracteres constantes nas populações, em especial o pequeno número de ramos em cada nó dos colmos e uma extensão apical na bainha das folhas dos ramos. Contudo, C. bradei e $C$. bambusoides também apresentam um pequeno número de ramos, mas podem ser diferenciadas especialmente pelo indumento das bainhas das folhas dos ramos, escabro em $C$. oxylepis e pilosa em $C$. bradei e indumento da face abaxial da folha do colmo de $C$. oxylepis.

Recentemente, Schiller et al. (2006) ampliaram a distribuição conhecida de Chusquea oxylepis para o sul da Bahia até Santa Catarina, de 0-1.000 m de altitude. Na Serra Bonita, foram encontrados vários indivíduos ocorrendo apenas no interior da floresta, entre 500 e $800 \mathrm{~m}$ de altitude, sob baixa intensidade luminosa. Todos os indivíduos ocorrentes na área de estudos estavam apenas em estágio vegetativo durante a realização do presente trabalho. Segundo Clark (2001), existem indícios de um ciclo de floração gregária de 16-17 anos para essa espécie.
1.3 Chusquea bradei L.G. Clark, Brittonia 48(2): 254, f. 2.1996.

Fig. 3e-f, 4a-h

Plantas perenes, lignificadas, escandentes, rizomas paquimorfos; colmos ca. $10 \mathrm{~m}$ alt., 27 mm diâm., sem uma faixa de cera branca abaixo dos nós; entrenós 12-17 cm compr., sólidos, com medula muito densa, esverdeados, hirsutos próximo aos nós, estes glabros; ramificação infravaginal, gema principal patente, perpendicular ao colmo, 5-20 ramos, 23-35 cm compr., ca. 1 mm diâm., nós não intumescidos. Folhas dos colmos com bainhas decíduas, hirsutas, margens ciliadas, cílios ca. 2 mm compr.; lâminas ca. $3 \times 0,2 \mathrm{~cm}$, triangulares, eretas, decíduas, pubescentes em ambas as faces, margens ciliadas, cílios ca. 1 mm compr.; lígula interna membranoso-ciliada, ca. 0,5 mm compr. Folhas dos ramos 7-15, bainhas pilosas, margens ciliadas, cílios ca. $1 \mathrm{~mm}$ compr., sem extensões apicais; lígula externa formando um colar ca. 0,5 $\mathrm{mm}$ compr., lígula interna membranoso-ciliada, ca. $1 \mathrm{~mm}$ compr., glabra a pubescente; pseudopecíolo ca. $2 \mathrm{~mm}$ compr., piloso em ambas as faces; lâminas 7,5-11,8× 0,8-1,9 cm, lanceoladas, cartáceas, ápice acuminado, base arredondada, assimétrica, face adaxial glabra, face abaxial com tricomas concentrados na base, margens escabras, esverdeadas, sem manchas vináceas. Inflorescências em panículas capitadas, congestas, subtentidas por brácteas espatiformes, 1,5-1,7 $\times 1,5-1,7 \mathrm{~cm}$, inclusas, ráquis pilosa, pedicelos pilosos. Espiguetas 7-8 $\times 3-5 \mathrm{~mm}$, glumas maiores que a espigueta; gluma I $3-4 \times 2 \mathrm{~mm}$, triangular, aristada, arista 3-4 mm compr., pilosa, margens escabras, 3-nervada; gluma II ca. $3 \times 2 \mathrm{~mm}$, triangular, aristada, arista 4-4,5 mm compr., pilosa, margens escabras, 1-nervada; gluma III 4-5 $\times 2 \mathrm{~mm}$, lanceolada a oval, aristada, arista 1-2 mm compr., pilosa próximo ao ápice, margens escabras, 5-nervada; gluma IV 4-5 $\times 2 \mathrm{~mm}$, lanceolada a oval, aristada, arista 1-2 mm compr., pilosa próximo ao ápice, margens escabras, 7nervada; lema ca. $6 \times 4 \mathrm{~mm}$, lanceolado a oval, agudo, piloso próximo ao ápice, margens escabras, 9-nervado; pálea ca. 5,5 ×4 mm, lanceolada, aguda, glabra a escabra, margens glabras, 6nervada. Frutos não vistos. 
Material selecionado: trilha da bapeba, 28.II.2008, fl., A. C. Mota 222 (HUEFS).

Chusquea bradei pode ser distinta das demais espécies ocorrentes na Serra Bonita tanto por caracteres vegetativos quanto reprodutivos. As folhas dos colmos apresentam bainhas hirsutas, as dos ramos têm bainhas nitidamente pilosas e o número de nervuras nas folhas dos ramos é bem menor que nas demais espécies, sempre abaixo de sete. Vale ressaltar que todos os indivíduos dessa espécie foram observados apenas em floração, não sendo encontradas amostras apenas em estágio vegetativo, as quais podem apresentar lâminas foliares de maior comprimento em algumas espécies. Panículas capitadas, fortemente contraídas e subtentidas por brácteas espatiformes, também são fundamentais para a identificação de $C$. bradei.

Essa espécie é conhecida para Espírito Santo e Bahia, ocorrendo em áreas montanhosas associadas à floresta atlântica, a 600-900 m de altitude (Clark 1996). Na Serra Bonita ocorre apenas no interior da floresta, em uma única trilha, a ca. $900 \mathrm{~m}$ de altitude, sob alta intensidade luminosa. Foram encontradas apenas duas touceiras de não mais que $1 \mathrm{~m}$ de diâmetro, e muito próximas uma da outra, cujos colmos se ramificam sobre as árvores formando uma densa cobertura. Existem poucas coletas de material fértil de $C$. bradei, oriundas de diferentes populações, que não indicam precisamente seu ciclo de floração (Clark 1996). Os indivíduos coletados tiveram registro de floração entre os meses de fevereiro a abril de 2008.

Esta espécie era conhecida apenas de outras três populações (na Bahia, no município de Una, e no Espírito Santo nos municípios de Castelo e Santa Tereza) (Clark 1996), portanto o reconhecimento de mais uma área de ocorrência amplia sua distribuicão e é de relevante importância para sua conservação.

\subsection{Chusquea sp. Fig. 3g-i, 4i-n}

Plantas perenes, lignificadas, semiescandentes, rizomas paquimorfos; colmos ca. 5 m alt., 4-6 mm diâm., os mais jovens com uma faixa de cera branca com aproximadamente
$1 \mathrm{~cm}$ larg. abaixo dos nós; entrenós ca. 24 cm compr., sólidos a semi-fistulosos em alguns pontos, medula pouco densa e mais ou menos esponjosa, com manchas castanhas a vináceas, com tricomas negros próximo aos nós, estes glabros; ramificação extravaginal, gema principal ascendente em direção ao ápice do colmo, (8)12-18 ramos, 20-34 cm compr., 11,5 mm diâm., nós não intumescidos. Folhas dos colmos com bainhas tardiamente decíduas, esparsamente pilosas e curto-escabras, margens ciliadas, cílios 1-2 mm compr.; lâminas ca. 2,3 $\times 1 \mathrm{~cm}$, triangulares, eretas, decíduas, escabras em ambas as faces, margens ciliadas, cílios 1-2 mm compr.; lígula interna membranosa, ca. $1 \mathrm{~mm}$ compr. Folhas dos ramos 5-6, bainhas pilosas, margens ciliadas, cílios ca. 2 mm compr., sem extensões apicais; lígula externa formando um colar 0,2-0,8 mm compr., lígula interna membranosa, ca. $1 \mathrm{~mm}$ compr., escabra; pseudopecíolo ca. $1 \mathrm{~mm}$ compr, face adaxial pilosa, face abaxial glabra; lâminas 7,9-14 × $1,1-1,8 \mathrm{~cm}$, lanceoladas, membranáceas, ápice acuminado, base subcordada, simétrica a levemente assimétrica, face adaxial esparsamente pilosa com maior concentração de tricomas na base, face abaxial glabra, margens escabras, esverdeadas, com manchas vináceas em toda sua extensão. Inflorescências não vistas.

Material selecionado: trilha da torre, 30.VI.2007, A.C. Mota 82 (HUEFS).

Dentre as espécies de Chusquea ocorrentes na Serra Bonita, Chusquea sp. pode ser reconhecida pela presença de colmos pouco lignificados, os mais jovens com uma faixa de cera branca com aproximadamente $1 \mathrm{~cm}$ de largura abaixo dos nós; entrenós com manchas castanhas a vináceas e lâminas das folhas dos ramos com manchas vináceas.

A medula pouco densa e mais ou menos esponjosa, sendo semi-fistulosa em alguns pontos dos colmos é bastante notável nas plantas vivas, lembrando os colmos de Lasiacis Griseb. (Panicoideae) e Alvimia C.E. Calderón (Bambusoideae). Após o processo de herborização, os tecidos internos dos colmos tornam-se colapsados, provavelmente devido a uma intensa perda de água, o que não foi 

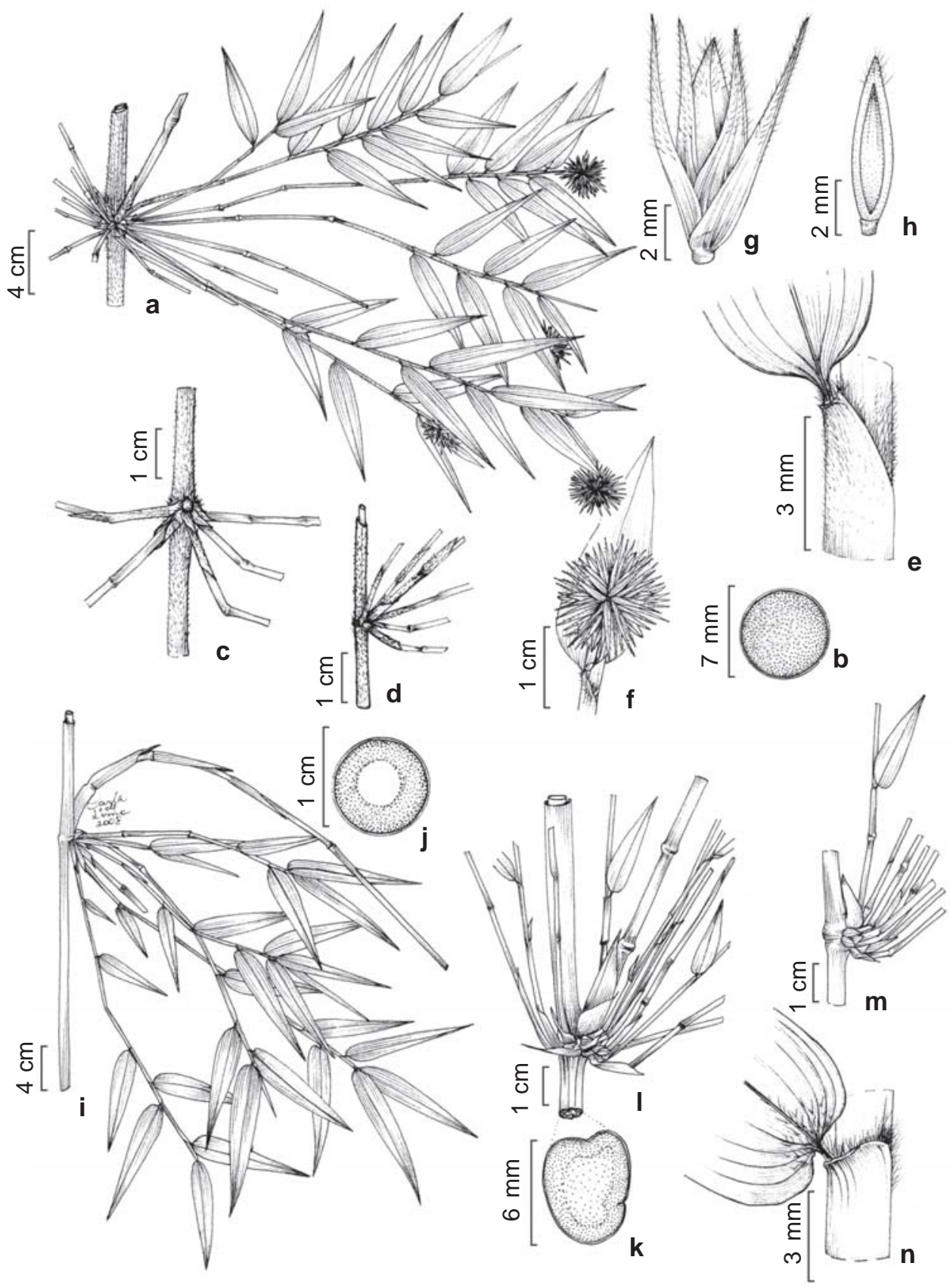

Figura 4 - a-h. Chusquea bradei - a. ramos com folhas e inflorescências; b. corte transversal do colmo; c. vista frontal da ramificação, mostrando gema principal patente; d. vista lateral da ramificação; e. detalhe da bainha da folha do ramo, pseudopecíolo e base da lâmina; f. inflorescência; g. espigueta; h. antécio, vista da pálea. i-n. Chusquea sp. - i. ramos com folhas; j. corte transversal do colmo; k. corte transversal do colmo colapsado; 1. vista lateral da ramificação, mostrando ramo principal desenvolvido; $\mathrm{m}$. vista lateral da ramificação, mostrando a gema principal ascendente; $\mathrm{n}$. detalhe da bainha, pseudopecíolo e base da lâmina. (a-h A.C. Mota 222 (HUEFS); i-n A.C. Mota 240 (HUEFS)).

Figure 4 - a-h. Chusquea bradei - a. branches with leaves and inflorescences; b. culm, transversal view; c. branching, frontal view, showing patent main bud; $d$. branching, lateral view; e. detail of the sheaths branch, pseudopetiole and base of the blade; f. inflorescence; g. spikelet; h. anthecium, palea view. i-n. Chusquea sp. - i. branches with leaves; j. culm, traversal view; k. collapsed culm, transversal view; 1. branching, lateral view, showing developed main branch; $\mathrm{m}$. branching, lateral view, showing the ascending main bud; $\mathrm{n}$. detail of the sheath branch, pseudopetiole and base of the blade. (a-h A.C. Mota 222 (HUEFS); i-n A.C. Mota 240 (HUEFS)). 
observado em nenhuma outra espécie de bambu ocorrente na área de estudos.

Dentre os materiais de Chusquea analisados nos herbários visitados e na literatura, nenhum deles apresentou morfologia semelhante aos materiais aqui considerados como Chusquea sp. A espécie está representada na área de estudo por uma única população, no interior da floresta e sob baixaintensidade luminosa. Não foi registrado nenhum evento de floração no período de execução deste trabalho.

2. Guadua Kunth, J. Phys. Chim. Hist. Nat. Arts 95: 150.

Guadua é caracterizado principalmente por apresentar colmos fistulosos e ramos espinescentes, com espinhos mais desenvolvidos nos nós inferiores do ramo principal (Londoño 2001). Além disso, trata-se do gênero de bambu com porte mais robusto entre os representantes brasileiros, tanto no que diz respeito à altura quanto no diâmetro dos colmos.

O gênero inclui 24 espécies ocorrentes do México à Argentina, com ca. 14 espécies no Brasil (Londoño 2001). Guadua tagoara (Nees) Kunth foi a única espécie desse gênero encontrada na área de estudos.

\subsection{Guadua tagoara (Nees) Kunth, Enum.} P1. 1: 434. 1833.

Fig. 5a-d, 6a-c

Plantas perenes, lignificadas, eretos e arqueando no ápice, rizomas paquimorfos; colmos 10-15(20) malt., 5-10 cm diâm.; entrenós (16)20$60(80) \mathrm{cm}$ compr., fistulosos, esverdeados, os mais jovens glaucos, híspidos, tricomas adpressos, nós escabros; ramificação intravaginal, 1-vários ramos, um deles dominante; ramos espinescentes, 1-3 espinhos. Folhas dos colmos com bainhas decíduas, largo-triangulares, face externa pubescente, com tricomas rígidos e escabros castanho-avermelhados, e macios trasparentes, margens glabras, face interna densamente estrigosa entre as nervuras, margens glabras; lâminas (2)3-5,5(7) × 9-10(13) cm, largotriangulares, eretas, decíduas, pubescentes, com tricomas macios transparentes e às vezes escabros, com tricomas castanho-avermelhados; lígula interna denso-ciliada, 1-2 mm compr. Folhas dos ramos 5-8(10), escabras no ápice, margens ciliadas; lígula externa formando colar ca. 0,8 mm compr., lígula interna membranosa, ca. 1,5 mm compr., glabra; pseudopecíolo 1-1,4 cm compr., glabro em ambas as faces; lâminas 22$25 \times 3,1-4,4$ cm, largo-lanceoladas, cartáceas, ápice agudo a acuminado, base assimétrica, com um lado arredondado e o outro lado subcordado, glabras em ambas as faces, margens escabras, esverdeadas e de coloração uniforme na face abaxial, sem uma faixa verde-escura marginal. Inflorescências não vistas.

Material selecionado: trilha da caixa d'água, 20.IV.2008, A.C. Mota 250 (HUEFS).

Guadua tagoara difere claramente dos outros bambus ocorrentes na área de estudos, pelo porte bastante robusto, podendo alcançar até $20 \mathrm{~m}$ de altura, e colmos grossos com 5$10 \mathrm{~cm}$ de diâmetro. Além disso, outras duas características principais a diferenciam das demais, a presença de ramos espinescentes e folhas do colmo largamente triangulares.

Ocorre na floresta atlântica, tanto em áreas baixas quanto montanas, da Bahia a Santa Catarina, entre 50 e $1.200 \mathrm{~m}$ de altitude (Londoño \& Clark 2002). O ciclo de floração desta espécie ainda precisa ser melhor estudado, entretanto, com base em informações dos espécimes de herbário, Londoño \& Clark (2002) indicaram um provável ciclo de dois anos. Ao contrário da maioria das Bambuseae, essa espécie não é monocárpica, somente alguns colmos florescem por vez (Londoño \& Clark 2002). Foi encontrada na Serra Bonita uma única população de G. tagoara no interior da floresta, formando uma grande touceira a aproximadamente $900 \mathrm{~m}$ de altitude, sob alta intensidade luminosa.

3. Merostachys Spreng., Syst. Veg. 1: 132, 249. 1824.

Merostachys caracteriza-se por apresentar os nós da porção mediana do colmo com uma única gema, que rapidamente desenvolve-se em 3-25 gemas secundárias, resultando em 3-muitos ramos não espinescentes, com inserção apsidada, ou seja, formando um arco e deixando um espaço triangular, além dos 


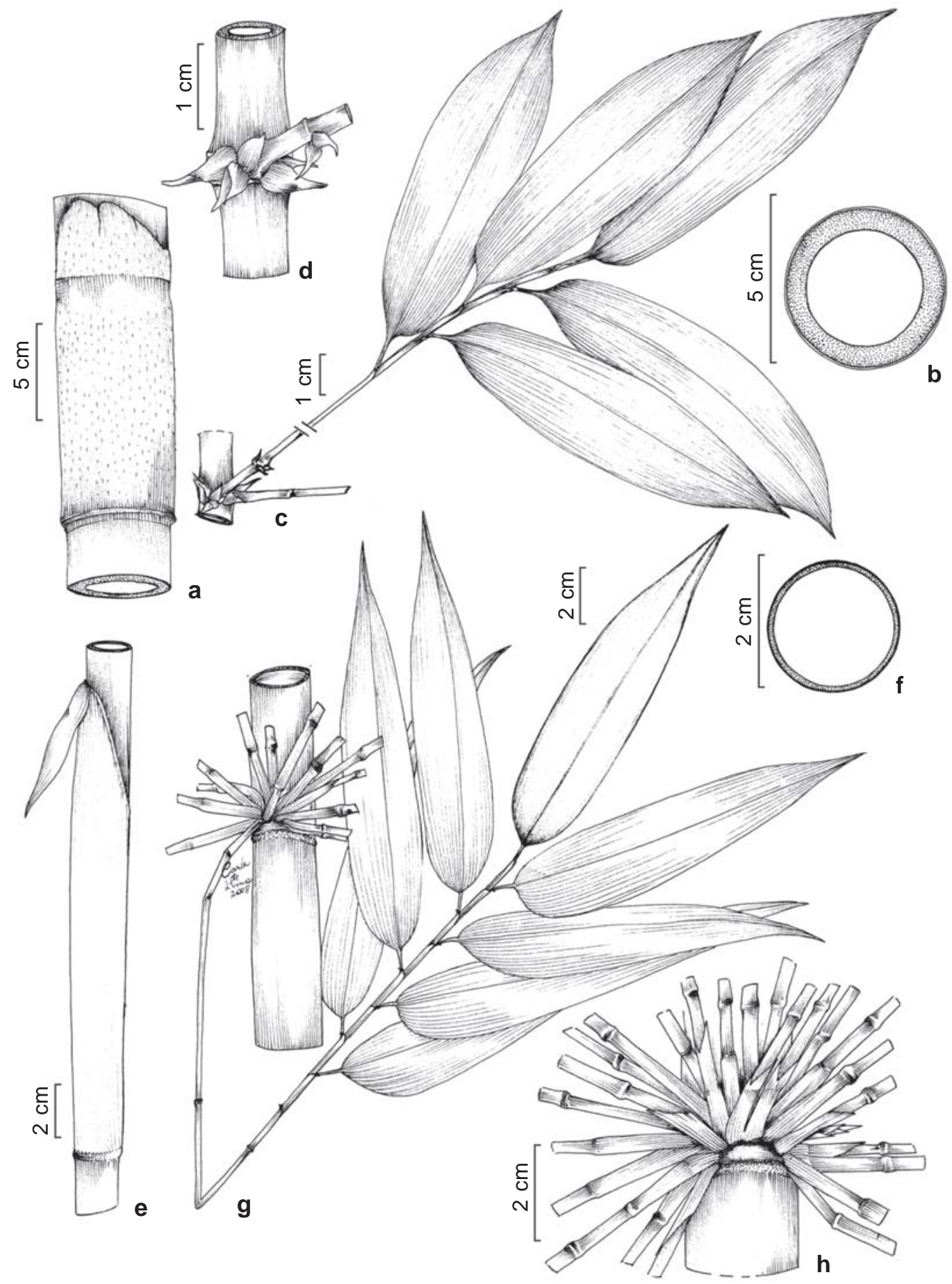

Figura 5 - a-d. Guadua tagoara - a. folha do colmo; b. corte transversal do colmo; c. ramo com folhas; d. detalhe da ramificação e ramos espinescentes. e-h. Merostachys neesii - e. folha do colmo; f. corte transversal do colmo; g. ramo com folhas; h. detalhe da ramificação apsidada (mostrando ausência de ramo dominante). (a-d A.C. Mota 250 (HUEFS); e R.P. Oliveira et al. 1235 (CEPEC); f-g A.C. Mota 203 (HUEFS); h A.C. Mota et al. 52 (CEPEC)).

Figure 5 - a-d. Guadua tagoara - a. culm leaf; b. culm, transversal view; c. branch with leaves; d. branching details and branches with spines. e-h. Merostachys neesii - e. culm leaves; f. culm, transversal view; g. branch with leaves; h. flabellate branching (showing absence of main branch). (a-d A.C. Mota 250 (HUEFS); e R.P. Oliveira et al. 1235 (CEPEC); f-g A.C. Mota 203 (HUEFS); h A.C. Mota et al. 52 (CEPEC)). 
ramos subiguais, sem um deles dominante (Sendulsky 2001a).

O gêneroé composto por aproximadamente 55 espécies ocorrentes nas Américas Central e do Sul, a maioria do Brasil (Sendulsky 2001a). Foram referidas 53 espécies de Merostachys para o Brasil (Filgueiras \& Santos-Gonçalves 2004), sendo que 10 estão restritas ao estado da Bahia (Sendulsky 1997). Na Serra Bonita, o gênero está representado por uma única espécie, M. neesii Rupr.

\subsection{Merostachys neesii Rupr., Bambuseae 37,} t. 10, f.31.1839.

Fig. 5e-h, 6d-h

Plantas perenes, lignificadas, eretas e arqueando no ápice, rizomas paquimorfos; colmos ca. 10 m alt., 1,6-3,2 cm diâm.; entrenós ca. $30 \mathrm{~cm}$ compr., fistulosos, verde-azulados, os mais jovens com uma cera esbranquiçada abaixo dos nós de ca. $5 \mathrm{~cm}$ larg., glabros, nós esbranquiçados com um colar de tricomas ou enegrescidos sem o colar de tricomas; ramificação apsidada, (10)25-64 ramos, sem um ramo dominante, (24)33-51 cm compr., 1,5-2 mm diâm., 2-3 nós, estes intumescidos, atro-purpúreos. Folhas dos colmos com bainhas tardiamente decíduas, lanceoladas, glabras, margens ciliadas, cílios 2-3 mm compr., sem fimbrias apicais; lâminas 5-11×0,8-1,1 cm, lanceoladas, reflexas, decíduas, glabras em ambas as faces, margens ciliadas, cílios 0,9-1 mm compr.; lígula externa rigída, 4,5-5 $\mathrm{mm}$ compr., lígula interna cartilaginosa, 1,8-2 mm compr., glabra. Folhas dos ramos 4-10, bainhas glabras, margens ciliadas, cílios ca. 0,5 mm compr., sem fimbrias apicais; lígula externa rigída, ca. 0,5 $\mathrm{mm}$ compr., lígula interna cartilaginosa, ca. $1 \mathrm{~mm}$ compr., glabra; pseudopecíolo 0,4-0,7 cm compr., glabro em ambas as faces; lâminas 13-20,5 × 1,6$3,2 \mathrm{~cm}$, lanceoladas, membranáceas, ápice acuminado, base arredondada, assimétrica, face adaxial glabra, face abaxial pilosa, margens escabras, esverdeadas de coloração não uniforme na face abaxial, com uma faixa verdeescura marginal. Inflorescências não vistas.

Material selecionado: trilha da pousada, 26.V.2007, A.C. Mota et al. 50 (CEPEC); trilha da bapeba, 25.I.2008, A.C. Mota 203 (HUEFS).
Algumas espécies de Merostachys apresentam longos intervalos de florescimento, entre 30 e 40 anos (Sendulsky 1995). Ainda assim, a maioria das coleções desse gênero encontradas em herbário, consiste em ramos floríferos fragmentados, quase sempre sem as partes vegetativas. Consequentemente, as descrições e as medidas dos caracteres vegetativos, quando disponíveis, são baseadas nos ramos floríferos, os quais, podem apresentar menores dimensões, e portanto, são pouco representativos em relação à planta como um todo (Sendulsky 1995), o que pode representar um entrave à identificação correta dos espécimes coletados em estágio vegetativo.

No caso de Merostachys neesii, coletada estéril na Serra Bonita, as medidas das lâminas e número de ramos por nó alcançaram tamanhos pouco maiores do que encontrado na literatura consultada. Porém, outros caracteres como altura e diâmetro dos colmos, ramos com 2-3 nós intumescidos e negros, 4-10 folhas por ramo são considerados fundamentais para sua identificação. Eespecialmente por apresentarem bainhas dos colmos e dos ramos sem fímbrias apicais, o que é raro no gênero.

Merostachys nessii foi referida para São Paulo e Rio de Janeiro (Sendulsky 2001b) e para a Bahia por Renvoize \& Longhi-Wagner (2008). Na Serra Bonita forma grandes touceiras, que ocorrem no interior e borda da floresta, sob alta intensidade luminosa. Em todo o período de coleta não foi registrado nenhum evento de floração em nenhuma das touceiras encontradas.

Essa espécie foi considerada ameaçada de extinção pela Resolução SMA 48 (Lista Oficial das espécies da Flora do Estado de São Paulo ameaçadas de extinção, de 22 de setembro de 2004), mas não consta na lista atual da flora brasileira ameaçada (MMA 2008).

4. Olyra L., Syst. Nat. (ed. 10) 1253, 1261, 1379, 12759.

Olyra caracteriza-se por apresentar colmos geralmente monomórficos, inflorescências em panículas abertas com espiguetas unissexuais, os ramos inferiores com espiguetas masculinas, com ou sem femininas terminais, os superiores 

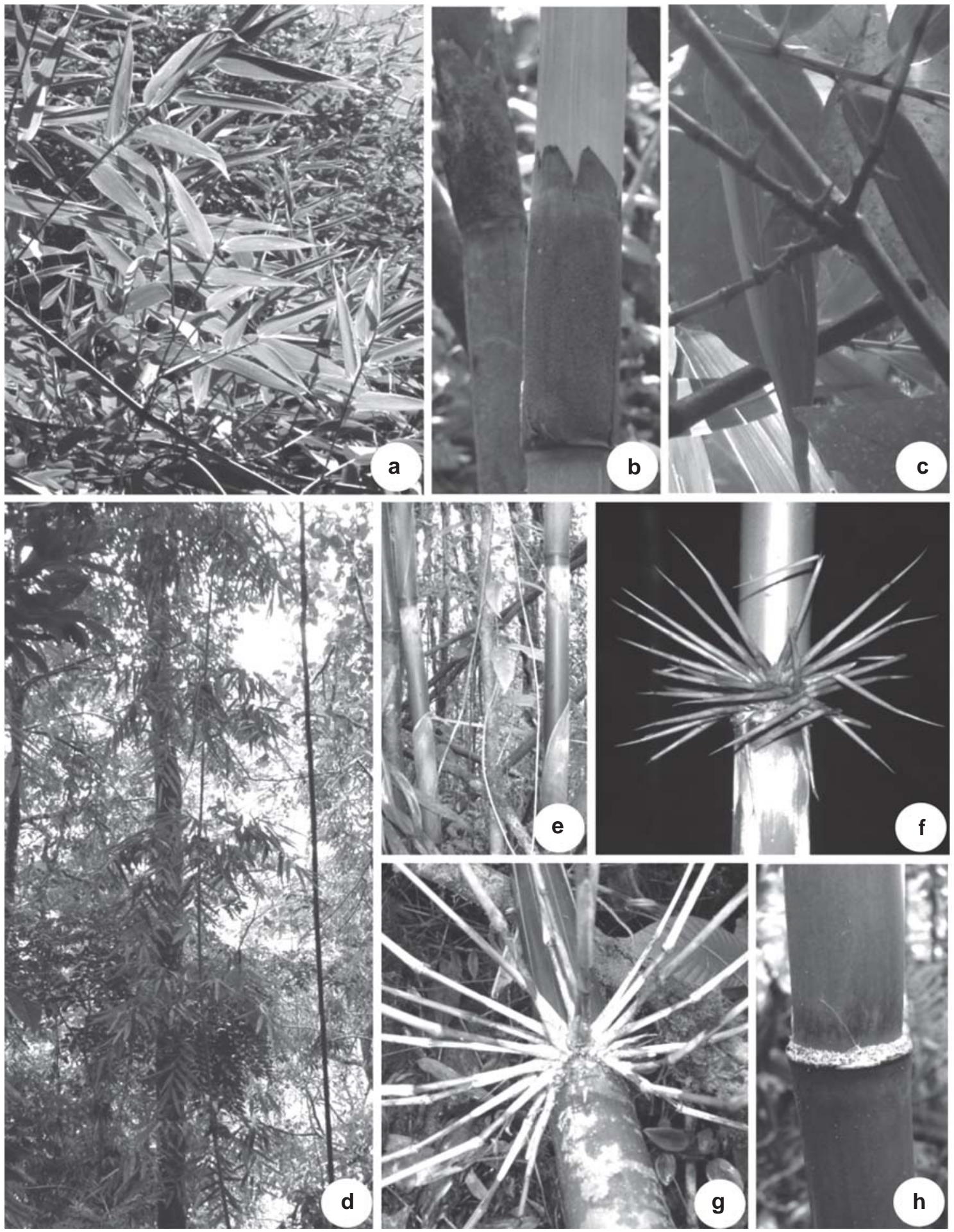

Figura 6 - a-c. Guadua tagoara - a. folhas dos ramos; b. folha do colmo; c. detalhe dos ramos espinescentes. d-h. Merostachys neesii - d. hábito; e. folhas dos colmos; f. gemas com igual espessura; g. detalhe da ramificação apsidada; h. região do nó. (a-c A.C. Mota 250 (HUEFS); d-e, g-h A.C. Mota 203 (HUEFS); f A.C. Mota et al. 50 (CEPEC)).

Figure 6 - a-c. Guadua tagoara - a. leaves branches; b. the culm leaf; c. branches with spines. d-h. Merostachys neesii - d. habit; e. culm leaves; f. detail of the buds with equal thickness; g. flabellate branching; h. region of the node. (a-c A.C. Mota 250 (HUEFS); d-e, g-h A.C. Mota 203 (HUEFS); f A.C. Mota et al. 50 (CEPEC)). 
com masculinas inferiormente e um número variado de espiguetas femininas terminais; pedicelos das espiguetas femininas espessados no ápice, estas desarticulando acima das duas glumas, com antécios geralmente lisos; espiguetas masculinas geralmente menores que as femininas e com três estames (Oliveira \& Longhi-Wagner 2001).

O gênero inclui 24 espécies neotropicais, florestais, ocorrentes do México e sudeste dos Estados Unidos até a Argentina e com grande diversidade no Brasil (Oliveira \& LonghiWagner 2005). Na Serra Bonita está representado por uma única espécie, Olyra latifolia L., sendo a maior diversidade desse gênero na Bahia diagnosticada para florestas baixas, litorâneas (Oliveira 2001).

4.1 Olyra latifolia L., Syst. Nat., ed. 10: 1261. 1759.

Fig. 7a-e, 8a

Plantas perenes, sublignificadas, cespitosas, eretas, rizomas paquimorfos; colmos monomórficos, 1-2 $\mathrm{m}$ alt., ca. $8 \mathrm{~mm}$ diâm., não ramificados ou ramificando apenas uma vez na região mediana; entrenós glabros a pilosos, nós pubescentes a pilosos. Folhas com bainhas pilosas, margens ciliadas, cílios ca. $0,5 \mathrm{~mm}$ compr.; lígula interna membranoso-ciliada, 0,5-1 mm compr., pubescente; pseudopecíolo 3-5 mm compr., escabro, piloso a hirsuto em ambas as faces; lâminas 13,9-24×2,9-5,5 cm, lanceoladas, cartáceas, ápice acuminado, base arredondada, assimétrica, escabras e com tricomas concentrados próximo ao pseudopecíolo em ambas as faces, margens escabras. Inflorescências em panículas, abertas, ca. $12 \mathrm{~cm}$ compr., ramos inferiores verticilados ou alternos com espiguetas masculinas inferiormente 1 espigueta feminina no ápice, ramos superiores alternos com espiguetas masculinas inferiormente e 1 feminina no ápice, ou apenas femininas, pedúnculos ca. $6 \mathrm{~cm}$ compr., escabros e pubescentes a pilosos, ráquis escabra a hirsuta, pedicelos escabros e pubescentes. Espiguetas femininas 1,5-1,6 $\times$ $0,3 \mathrm{~cm}$; gluma inferior $1,5-1,6 \mathrm{~cm}$ compr., oval, aristada, arista ca. $1 \mathrm{~cm}$ compr., glabra a escabra, margens glabras ou escabras e ciliadas na região basal, 5-nervada; gluma superior ca. 0,8 $\times 0,3$ $\mathrm{cm}$, oval, acuminada, glabra a escabra, margens glabras a escabras, 5-nervada; antécios 5-5.5 mm compr., elíptico-ovalados, lisos, brilhantes sem manchas. Espiguetas masculinas não vistas. Frutos não vistos.

Material selecionado: trilha da pousada, 28.02.2008, fl., A.C. Mota 229 (HUEFS).

Olyra latifolia apresenta morfologia característica, e dentre as espécies ocorrentes na área de estudos, pode ser confundida apenas com Parodiolyra micrantha (Kunth) Davidse \& Zuloaga, quando estéreis. Elas se parecem no aspecto geral das plantas, diferenciando-se, além dos caracteres constantes na chave, no seguinte aspecto reprodutivo: $O$. latifolia apresenta inflorescências com espiguetas masculinas inferiormente em cada ramo das panículas, os quais portam uma feminina no ápice, versus inflorescências com ramos inferiores apenas portando espiguetas masculinas e ramos superiores compostos exclusivamente de espiguetas femininas em $P$. micrantha.

A espécie ocorre desde o sudeste dos Estados Unidos (Flórida), Caribe, México Central até a Argentina e Paraguai, ocorrendo também na África e Madagáscar (Soderstrom \& Zuloaga 1989; Judziewicz et al. 1999), nas florestas tropicais, áreas alteradas e de transição para cerrado (Oliveira \& Longhi-Wagner 2001), entre 10 a 900 m altitude (Renvoize 1984). Coletada fértil durante o ano todo (Oliveira \& LonghiWagner 2001). Na Serra Bonita, são encontradas diversas touceiras nas clareiras e nas bordas da floresta, sob alta intensidade luminosa. Foi coletada fértil em fevereiro e abril.

5. Parodiolyra Soderstr. \& Zuloaga, Smithsonian Contr. Bot. 69: 64. 1989.

Parodiolyra caracteriza-se por apresentar colmos monomórficos; inflorescências em panículas abertas com espiguetas unissexuais, os ramos inferiores portando somente espiguetas masculinas e os superiores apenas femininas, ou com espiguetas masculinas inferiormente $\mathrm{e}$ femininas terminais; pedicelos de ambas as espiguetas filiformes; espiguetas femininas desarticulando abaixo das duas glumas, com antécios geralmente foveolados; espiguetas 


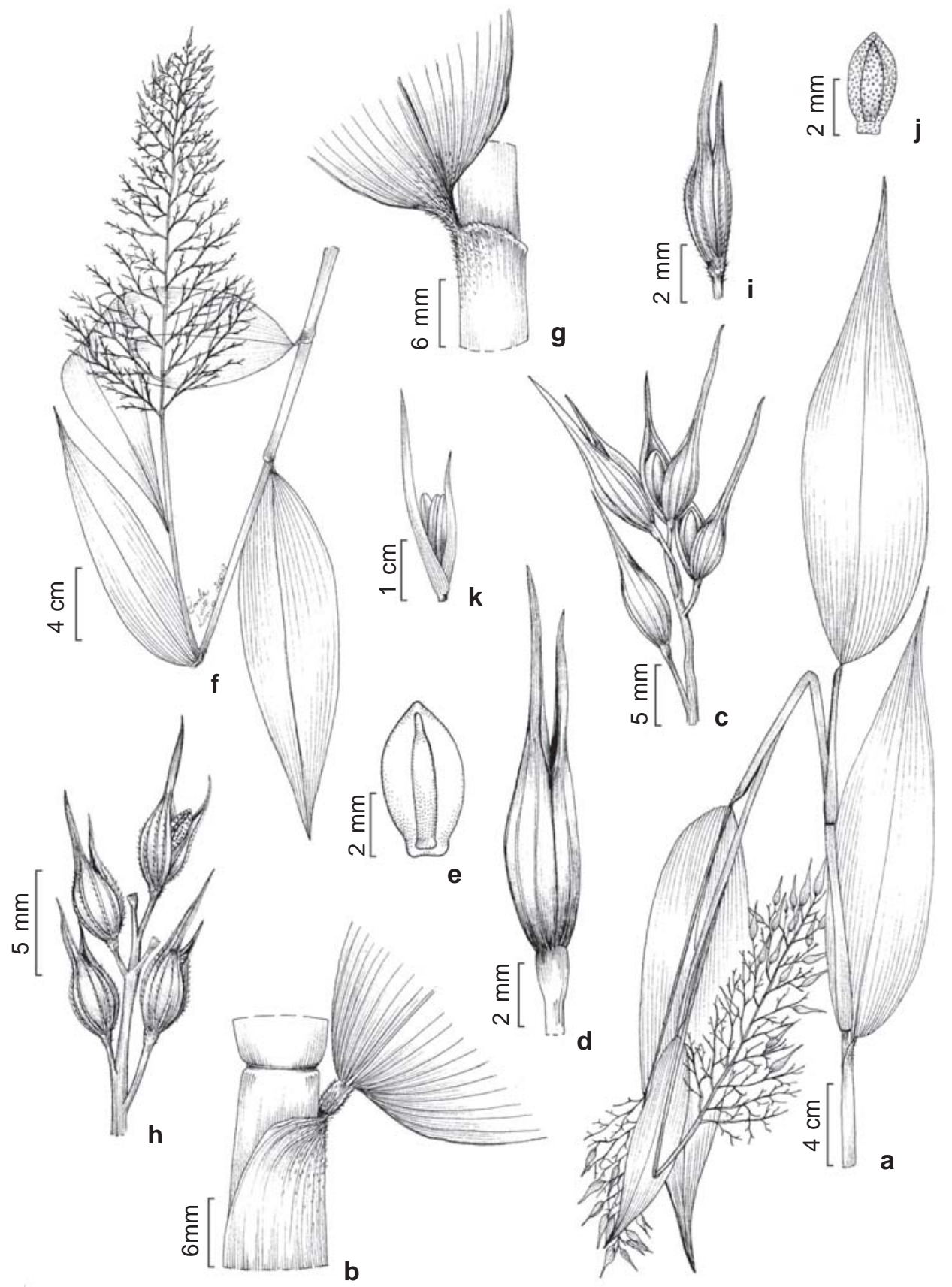

Figura 7 - a-e. Olyra latifolia - a. porção apical do colmo florífero b. detalhe do ápice da bainha da folha do ramo, pseudopecíolo e base da lâmina; c. ramo florífero e aspecto do pedicelo; d. espigueta feminina; e. antécio feminino, vista da pálea. f-k. Parodiolyra micrantha - f. porção superior do colmo florífero; g. detalhe do ápice da bainha da folha do ramo, pseudopecíolo e base da lâmina; h. ramo florífero e aspecto do pedicelo; i. espigueta feminina; j. antécio feminino, vista da pálea; k. espigueta masculina. (a-b A.M. Amorim et al. 6993 (CEPEC); c-e A.C. Mota 229 (HUEFS); f-g R.A.X. Borges et al. 311 (CEPEC); h-k A.C. Mota 200 (HUEFS)).

Figure 7 - a-e. Olyra latifolia - a. apical part of the inflorescence branch; b. detail of the apex of sheath branch, pseudopetiole and base blade; c. inflorescence branch and pedicel; d. female spikelet; e. female anthecium, palea view. f-k. Parodiolyra micrantha f. superior part of the inflorescence branch; g. details of the apex of sheath branch, pseudopetiole and base blade; h. inflorescence branch and pedicel; i. female spikelet; j. female anthecium, palea view; k. male spikelet. (a-b A.M. Amorim et al. 6993 (CEPEC); c-e A.C. Mota 229 (HUEFS); f-g R.A.X. Borges et al. 311 (CEPEC); h-k A.C. Mota 200 (HUEFS)). 
masculinas de comprimento subigual ou mais longas que as femininas e com três estames (Oliveira \& Longhi-Wagner 2001).

O gênero inclui cinco espécies florestais, distribuídas da Costa Rica até o Paraguai e sul do Brasil (Oliveira \& Longhi-Wagner 2001). Na Serra Bonita está representado por uma única espécie, Parodiolyra micranta (Kunth) Davidse \& Zuloaga.

5.1 Parodiolyra micrantha (Kunth) Davidse \& Zuloaga, Novon 9: 590. 1999.

Fig. $7 f-k, 8 b$

Plantas perenes, sublignificadas, cespitosas, eretas, rizomas paquimorfos; colmos monomórficos, ca. $1 \mathrm{~m}$ alt., ca. $6 \mathrm{~mm}$ diâm., não ramificados; entrenós glabros a pubescentes próximo aos nós, estes pubescentes. Folhas com bainhas escabras ou pubescentes, margens ciliadas, cílios ca. $1 \mathrm{~mm}$ compr.; lígula interna membranoso-ciliada, ca. 0,8 mm compr., pubescente; pseudopecíolo 1$5 \mathrm{~mm}$ compr., pubescente em ambas as faces; lâminas 13,5-31 × 4,8-9,5 cm, lanceoladas, cartáceas, ápice acuminado, base subcordada, simétrica a levemente assimétrica, face adaxial pubescente na região basal, face abaxial escabra, com tricomas negros e pubescente na região basal, margens escabras e ciliadas na região basal. Inflorescências em panículas, abertas, 11-37 × 4,5-23 cm, ramos inferiores verticilados com espiguetas masculinas, ramos superiores alternos com espiguetas femininas, pedúnculos ca. $4 \mathrm{~cm}$ compr., pubescentes a pilosos, ráquis escabra e pilosa, pedicelos pilosos. Espiguetas femininas 0,9-1,4 × 0,15$0,2 \mathrm{~cm}$; gluma inferior $0,9-1,4 \mathrm{~cm}$ compr., oval, aristada, arista 0,5-0,8 cm compr., escabra e pilosa nas nervuras, margens escabras, 5nervada; gluma superior $0,6-0,7 \times 0,15 \mathrm{~cm}$ compr., oval, aristada, arista $0,2-0,3 \mathrm{~cm}$ compr., escabra e pilosa nas nervuras, margens escabras, 3-nervada; antécios ca. 3,5 mm compr., oval, foveolados, opacos com manchas marrons escuras. Frutos não vistos. Espiguetas masculinas 5,5-9 $\times 1 \mathrm{~mm}$; sem glumas; lema 5,5-9 mm compr., lanceolado, aristado, arista
2-3,5 mm compr., escabro, margens escabras, 5-nervado; pálea 3,5-5 mm compr., lanceolada, aguda, escabra, margens glabras, 2-nervada, anteras 3-4 mm compr.

Material selecionado: trilha da pousada, 26.V.2007, A.C. Mota et al. 55 (CEPEC).

Parodiolyra micrantha é amplamente distribuida na América do Sul, ocorrendo na Colômbia, Venezuela, Andes, Peru, Bolívia, Argentina, Paraguai e Brasil, em fragmentos de floresta atlântica secundária, bordas de floresta e áreas alteradas (Oliveira \& LonghiWagner 2001), entre 20 e $1.065 \mathrm{~m}$ altitude (Renvoize 1984) e com registros de floração para os meses de junho a fevereiro (Oliveira \& Longhi-Wagner 2001). Na Serra Bonita, foram encontradas diversas touceiras nas clareiras e nas bordas da floresta, sob alta intensidade luminosa. Foi observada em floração nos meses de maio, agosto, novembro e dezembro.

6. Diandrolyra Stapf, Bull. Misc. Inform. Kew 1906: 204.

Diandrolyra apresenta colmos dimórficos, os floríferos curtos em relação aos vegetativos, e portando apenas uma folha com lâmina bastante desenvolvida, a qual recobre e esconde a inflorescência, dando às plantas uma aparência de sempre-estéril (Oliveira \& Clark 2009). As inflorescências são racemosas, compostas de pares de espiguetas unissexuais e subiguais, cada par formado por uma espigueta feminina e uma masculina adjacente. Distinguese ainda dos demais gêneros de bambus pela presença de apenas dois estames (três, nos demais). $\mathrm{Na}$ verdade, as espiguetas tratadas como masculinas nesse gênero são bissexuais, mas funcionalmente masculinas (Oliveira 2001).

O gênero é composto por três espécies endêmicas da floresta atlântica (Judziewicz et al. 1999; Clark 2001), uma delas descrita recentemente (Oliveira \& Clark 2009). Na Serra Bonita foi registrada uma única população, aqui tratada como Diandrolyra sp., por apresentar caracteres intermediários entre duas espécies conhecidas desse gênero. 

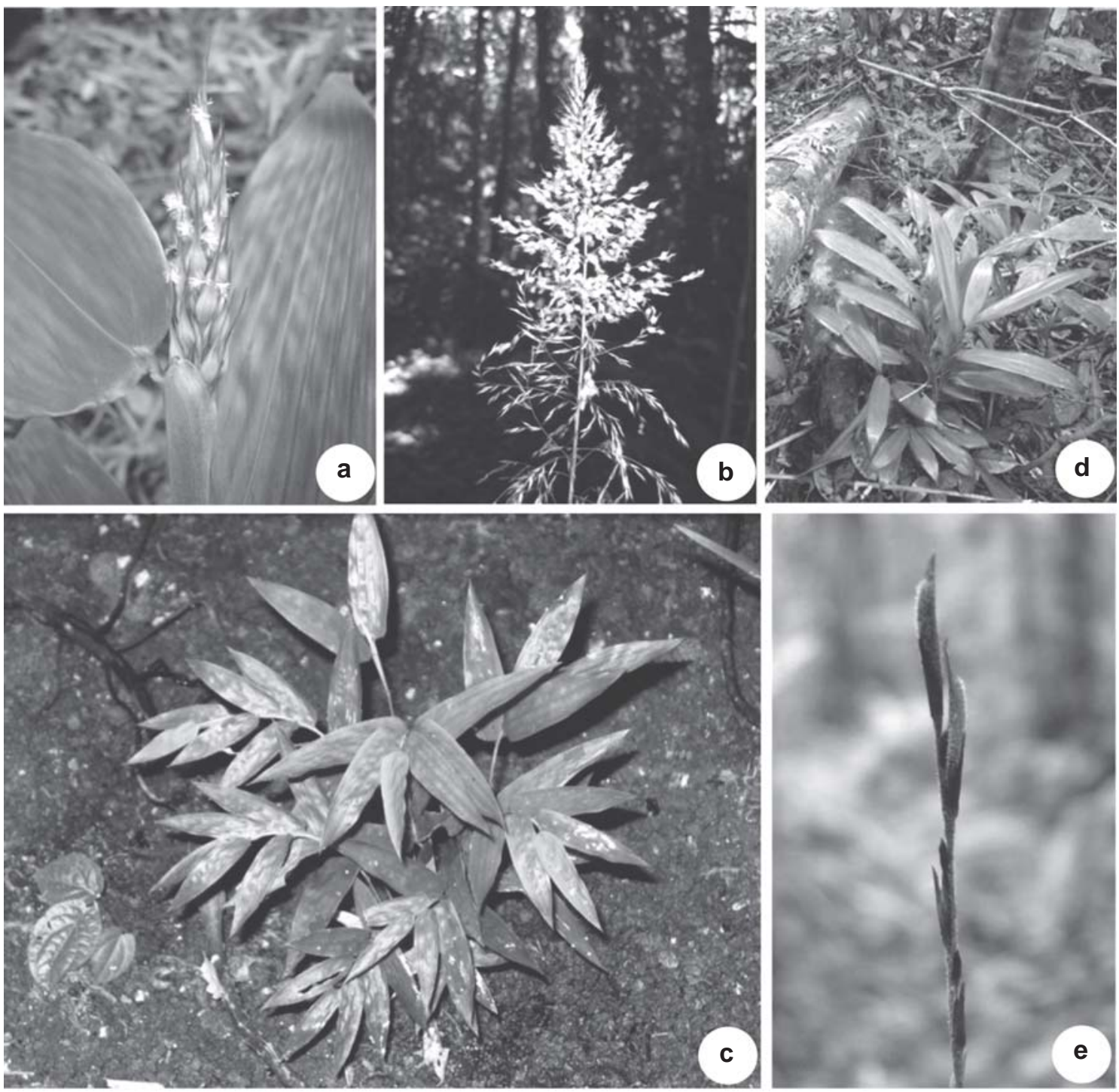

Figura 8 - a. Olyra latifolia - inflorescência jovem. b. Parodiolyra micrantha - inflorescência. c. Diandrolyra sp. hábito. d-e. Pharus lappulaceus - d. hábito; e. detalhe das espiguetas femininas sésseis e masculinas pediceladas. (a $A$. $C$. Mota 229 (HUEFS); b A. C. Mota et al. 55 (CEPEC); c R. P. Oliveira et al. 1238 (CEPEC); d-e A. C. Mota 231 (HUEFS)).

Figure 8 - a. Olyra latifolia - young inflorescence. b. Parodiolyra micrantha - inflorescence. c. Diandrolyra sp. - habit. de. Pharus lappulaceus - d. habit; e. detail of the sessile female spikelet and pedicelate male spikelet. (a A.C. Mota 229 (HUEFS); b A. C. Mota et al. 55 (CEPEC); c R. P. Oliveira et al. 1238 (CEPEC); d-e A. C. Mota 231 (HUEFS).

\subsection{Diandrolyra sp.}

Fig. 8c, 9a-e

Plantas perenes, herbáceas, cespitosas, eretas, sem rizomas; colmos dimórficos, os vegetativos 16-34 cm alt., ca. $1 \mathrm{~mm}$ diâm., entrenós e nós pubescentes a glabros, com 311 folhas, os floríferos ca. $13,5 \mathrm{~cm}$ alt., ca. 0,7 mm diâm., entrenós e nós glabros, com 1 folha. Folhas do colmo vegetativo com bainhas pubescentes, margens glabras; sem lígula externa, lígula interna membranosa, ca. 0,2 mm compr., glabra; pseudopecíolo ca. $1 \mathrm{~mm}$ compr., pubescente em ambas as faces; lâminas 4,5$9 \times 0,7-1,9 \mathrm{~cm}$, lanceoladas a oval-lanceoladas, ápice acuminado, base arredondada, levemente assimétrica, face adaxial escabra, face abaxial pubescente, margens escabras, membranáceas. Folhas do colmo reprodutivo com bainhas pubescentes, margens glabras; lígula interna 
membranoso-ciliada, ca. 0,2 mm compr., pubescente; pseudopecíolo ca. $2 \mathrm{~mm}$ compr., glabro em ambas as faces; lâminas 4,4-5 ×1$1,1 \mathrm{~cm}$, lanceoladas, membranáceas, ápice acuminado, base arredondada, levemente assimétrica, escabra em ambas as faces, margens escabras. Inflorescências em racemos, ca. $2 \mathrm{~cm}$ compr., com 5 pares de espiguetas femininas e masculinas, e 1 espigueta feminina no ápice, pedúnculos ca. $2 \mathrm{~mm}$ compr., escabros, ráquis escabra, pedicelos escabros. Espiguetas femininas ca. $6 \times 2 \mathrm{~mm}$; gluma inferior ca. $6 \times 2 \mathrm{~mm}$, elíptica, acuminada, escabra na região apical e pilosa nas nervuras e na base, margens glabras, 7-nervada; gluma superior ca. $5,8 \times 2 \mathrm{~mm}$, elíptica, acuminada, escabra na região apical e pilosa nas nervuras e na base, margens glabras, 7-nervada; lema ca. 4,5 × 1,5 mm, lanceolado, agudo, escabro na região apical, margens glabras; pálea ca. 4 $\times 1,2 \mathrm{~mm}$, lanceolada, aguda, escabra na região apical, margens glabras. Frutos não vistos. Espiguetas masculinas não vistas.

Material selecionado: próximo ao grotão (trilha da bapeba), 15.III.2007, fl. R.P. Oliveira et al. 1238 (CEPEC).

O material pertencente ao gênero Diandrolyra diferencia-se dos demais bambus coletados na Serra Bonita pelo hábito delicado, não ramificado, com colmos dimórficos e inflorescência racemosa. Embora as espiguetas estaminadas não tenham sido observadas no material coletado, as quais são fundamentais para reconhecimento do gênero devido ao número reduzido de estames, os demais caracteres acima descritos foram suficientes para identificação.

Uma única população com essa morfologia foi coletada na área de estudos, a qual representa um grande problema taxonômico por apresentar caracteres intermediários entre duas espécies formalmente descritas desse gênero, Diandrolyra bicolor Stapf e D. tatiane Soderstr. \& Zuloaga. Análises preliminares da superfície foliar em MEV não foram satisfatórias para delimitar esses três táxons, e portanto, estudos mais detalhados estão em andamento objetivando resolver essa questão.
A única população existente de Diandrolyra na Serra Bonita foi acompanhada durante todo o período de coletas, entretanto sua floração foi observada uma única vez, em março de 2007. Trata-se de uma população muito pequena, localizada em um grotão de afloramento rochoso, com baixa intensidade luminosa e elevada umidade.

\section{Pharoideae}

Pharoideae é composta apenas pela tribo Phareae, que inclui 12 espécies, sete das quais são exclusivamente americanas (GPWG 2001). São tipicamente florestais e representadas no Brasil por quatro espécies pertencentes ao gênero Pharus P. Browne (Judziewicz et al. 2000).

7. Pharus P.Browne, Civ. Nat. Hist. Jamaica 344, t. 38, f. 3. 1756.

Pharus caracteriza-se por apresentar folhas longo-pseudopecioladas, lâminas com face abaxial voltada para cima pela torção do pecíolo de $180^{\circ}$, nervuras longitudinais laterais ligadas por nervuras transversais; inflorescências com espiguetas unissexuais, sendo femininas e masculinas distribuídas aos pares, ou as primeiras solitárias, as femininas subsésseis e mais desenvolvidas que as masculinas longamente pediceladas e lema das espiguetas femininas recoberto por tricomas uncinados (aderentes).

O gênero possui sete espécies distribuidas do sudeste dos Estados Unidos até a Argentina e o Uruguai, em florestas tropicais úmidas (Longhi-Wagner 2001). As quatro espécies brasileiras de Pharus foram citadas para a Bahia (Renvoize 1984) e na Serra Bonita está representado por uma única espécie, $P$. lappulaceus Aubl.

7.1 Pharus lappulaceus Aubl., Hist. Pl. Guiane 2: 859. $1775 . \quad$ Fig. 8d-e, 9f-i

Plantas perenes, herbáceas, cespitosas, eretas a decumbentes, sem rizomas; colmos ca. $1 \mathrm{~m}$ alt., $3 \mathrm{~mm}$ diâm.; entrenós glabros a escabros, nós glabros a escabros. Folhas com bainhas escabras, margens glabras; lígula interna membranoso-franjada, ca. 1,5 mm compr., escabra; pseudopecíolo 1,5-5 cm compr., escabro 


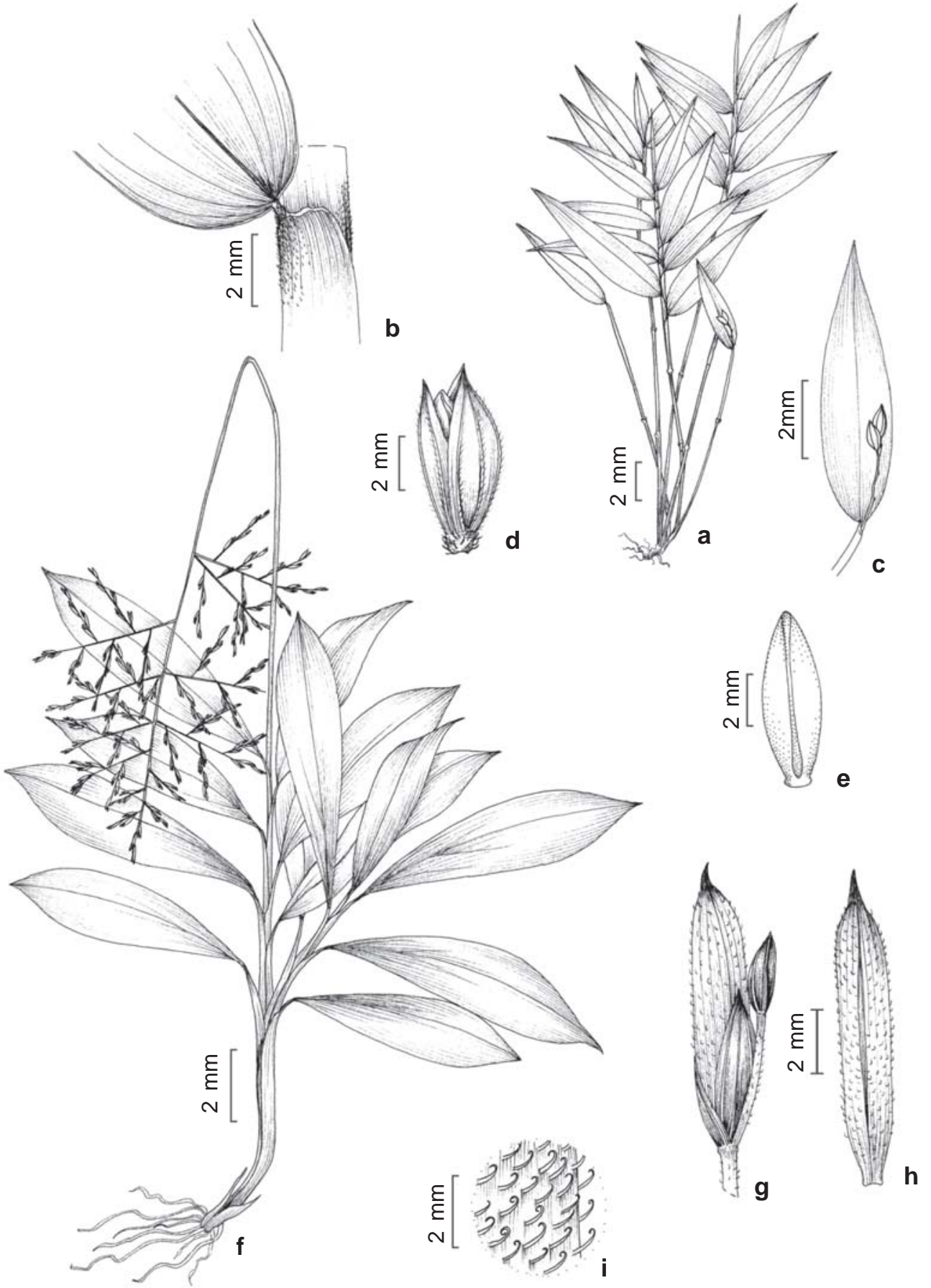

Figura 9-a-e. Diandrolyra sp. - a. hábito; b. detalhe do ápice da bainha, pseudopecíolo e base da lâmina; c. inflorescência; d. espigueta feminina; e. antécio feminino, vista da pálea. f-i. Pharus lappulaceus -f. hábito; g. par de espiguetas, com feminina séssil e masculina pedicelada; h. antécio feminino, vista da pálea; i. detalhe dos tricomas uncinados do lema feminino. (ae R.P. Oliveira et al. 1238 (CEPEC); f-i A.C. Mota 231 (HUEFS)).

Figure 9 - a-e. Diandrolyra sp. - a. habit; b. details of the apex sheath, pseudopetiole and base of the blade; c. inflorescence; d. female spikelet; e. female anthecium, palea view. f-i. Pharus lappulaceus - f. habit; g. pair of spikelets, with sessile female and pedicelate male spikelet; $h$. female anthecium, palea view; i. detail of uncinate hairs in the female lemma. (a-e R.P. Oliveira et al. 1238 (CEPEC); f-i A.C. Mota 231 (HUEFS)). 
em ambas as faces; lâminas 13,5-20,9 × 2,4$3,6 \mathrm{~cm}$, oblanceoladas, cartáceas, ápice acuminado, base atenuada, simétrica, curto-escabra em ambas as faces, margens curto-escabras. Inflorescências em panículas, abertas, (8)16$20 \mathrm{~cm}$, pedúnculos 69,5-70,5 cm compr., escabros, ráquis com tricomas uncinados, pedicelos escabros, com tricomas uncinados. Espiguetas femininas subsésseis, até $1 \mathrm{~mm}$ compr., as masculinas longo-pediceladas, 3-4 mm compr. Espiguetas femininas 8-9 mm compr.; gluma inferior 3,5-4 $\times 1 \mathrm{~mm}$, lanceolada a oval, aguda a obtusa, escabra, margens glabras, 5-nervada; gluma superior ca. $4 \times 1 \mathrm{~mm}$, lanceolada, aguda, escabra, margens glabras, 3-nervada; antécios ca. $7 \times 1 \mathrm{~mm}$, oblongos, com lema curvo na porção superior e recoberto por tricomas uncinados. Frutos não vistos. Espiguetas masculinas ca. $2 \times 0,5 \mathrm{~mm}$; lema ca. $2 \times 0,8 \mathrm{~mm}$, lanceolado, agudo, escabro, margens glabras; pálea ca. 2 $\times 1 \mathrm{~mm}$, lanceolada, aguda, escabra, margens glabra; estames ca. $2 \mathrm{~mm}$ compr.

Material selecionado: trilha da pousada, 24.XI.2007, fl., A.C. Mota 199 (HUEFS).

Pharus lappulaceus pode ser distinta das demais espécies de Poaceae ocorrentes na Serra Bonita pelos longos pseudopecíolos (1,5$5 \mathrm{~cm}$ compr.) torcidos $180^{\circ}$, fazendo com que a face abaxial da lâmina foliar permaneça voltada para cima. Além disso, apresenta espiguetas unissexuais distribuídas aos pares, a pistilada maior e subséssil (até $1 \mathrm{~mm}$ compr.) e a estaminada menor e longamente pedicelada (pedicelos de 3-4 mm compr.). O lema da espigueta pistilada é curvo na porção superior e recoberto por tricomas uncinados (aderentes).

Ocorre do sudeste dos Estados Unidos até a Argentina, Uruguai e Brasil, no interior de florestas úmidas e ripárias (Longhi-Wagner 2001), do nível do mar até 814 m de altitude (Renvoize 1984), florescendo de dezembro a maio (Longhi-Wagner 2001). Na Serra Bonita, uma única touceira foi encontrada no interior da floresta, a aproximadamente $600 \mathrm{~m}$ de altitude, sob pouca intensidade luminosa, florescendo entre os meses de novembro a fevereiro.

\section{Agradecimentos}

Às agências financiadoras FAPESB (Fundação de Amparo à Pesquisa do Estado da Bahia) e CAPES (Coodenação de Aperfeiçoamento de Pessoal de Nível Superior), pela bolsa de Mestrado concedida à primeira autora. Aos proprietários da RPPN Serra Bonita, Vitor Beckere Clemira Souza, pelo apoio logístico e ao guarda-parque Roni, pelo auxílio nas coletas. Aos curadores e funcionários dos herbários consultados, pelo acesso às coleções, em especial ao Dr. André Amorim, curador do CEPEC, pelo apoio logístico e empréstimo das coleções. À Carla de Lima pelas ilustrações.

\section{REFERÊNCIAS BIBLIOGRÁFICAS}

Amorim, A.M.; Fiaschi, P.; Jardim, J.G.; Thomas, W.W.; Clifton, B. \& Carvalho, A.M. 2005. The Vascular plants of a forest fragment in Southern Bahia, Brazil. Sida 21(3): 1726-1752.

Burman, A.G. 1985. Nature and composition of the grass flora of Brazil. Willdenowia 15: 211-233.

Cardoso, D.B.O.S. \& Queiroz, L.P. 2008. Floristic composition of seasonally dry tropical forest fragments in central Bahia, northeastern Brazil. Journal of the Botanical Research Institute of Texas 2(1): 551-573.

Carvalho-Sobrinho, J.G. \& Queiroz, L.P. 2005. Composição Florística de um fragmento de Mata Atlantica na Serra da Jibóia, Santa Terezinha, Bahia, Brasil. Sitientibus Série Ciências Biológicas 5(1): 20-28.

Clark, L.G. 1990. Diversity and biogeography of neotropical bamboos (Poaceae: Bambusoideae). Acta Botanica Brasilica 4: 125-132.

Clark, L.G. 1995. Diversity and distribution of the Andean woody bamboos (Poaceae: Bambusaeae). In: Churchill, S.P.; Balslev, H.; Forero, E. \& Luteyn, J. (eds.). Biodiversity and conservation of neotropical montane forests. New York Botanical Garden, New York. Pp. 501-512.

Clark, L.G. 1996. Four new species of Chusquea (Poaceae: Bambusoideae) and allies in Brazil. Brittonia 48: 250-262.

Clark, L.G. 1997. Diversity, biogeography, and evolution in Chusquea (Poaceae: Bambusoideae). In: Chapman, G. (ed.). The Bamboos. Academic Press, London. Pp. 33-44.

Clark, L.G. 2001. Chusquea Kunth. In: Wanderley, M.G.L.; Shepherd, G.J. \& Giulietti, A.M. (orgs.). 
Flora Fanerogâmica do Estado de São Paulo. Volume I. Poaceae. Instituto de Botânica, São Paulo, Brasil. Pp. 24-36.

Filgueiras, T.S. \& Santos-Gonçalves, A.P. 2004. A checklist of the basal grasses and bamboos in Brazil (Poaceae). Journal of the American Bamboo Society 18(1): 7-18.

GPWG (The Grass Phylogeny Working Group). 2001. Phylogeny and subfamilial classification of the grasses (Poaceae). Annals of the Missouri Botanical Garden 88: 373-457.

Harley, R.M. \& Simmons, N.A. 1986. Florula of Mucugê, Chapada Diamantina, Brazil. Royal Botanic Gardens, Kew. 228p.

Holmgren, P.K. \& Holmgren, N.H. 2007. Index Herbariorum. Disponível em: http://sweetgum. nybg.org/ih/ Acesso em: 10 outubro 2008.

IBAMA (Instituto Brasileiro do Meio Ambiente e dos Recursos Naturais Renováveis). 2004. Decreto de criação da RPPN Serra Bonita: $\mathrm{n}^{\circ}$ 15, de 04 de março de 2004; $n^{\circ} 16$, de 04 de março de 2004; $\mathrm{n}^{\circ} 33$, de 09 de março de 2004; $\mathrm{n}^{\circ} 36$, de 09 de março de 2004.

Judziewicz, E.J.L.; Clark, L.G.; Londoño, X. \& Stern, M.J. 1999. American Bamboos. Smithsonian Institution Press, Washington, D.C. 392p.

Judziewicz, E.J.L.; Soreng, R.J.; Davidse, G.; Peterson, P.M.; Filgueiras, T.S. \& Zuloaga, F.O. 2000. Catalogue of New World grasses (Poaceae): I. Subfamilies Anomochlooideae, Bambusoideae, Ehrhartoideae, and Pharoideae. Department of Botany, National Museum of Natural History, Washington, D.C. 128p.

Londoño, X. 2001. Guadua Kunth. In: Wanderley, M.G.L.; Shepherd, G.J. \& Giulietti, A.M. (orgs.). Flora fanerogâmica do estado de São Paulo. Volume I. Poaceae. Instituto de Botânica, São Paulo, Brasil. 292p.

Londoño, X. \& Clark, L.G. 2002. Three new taxa of Guadua (Poaceae: Bambusoideae) from South America. Novon 12: 64-76.

Longhi-Wagner, H.M. 2001. Pharus P. Browne. In: Wanderley, M.G.L.; Shepherd, G.J. \& Giulietti, A.M. (orgs.). Flora fanerogâmica do estado de São Paulo. Volume I. Poaceae. Instituto de Botânica, São Paulo, Brasil. Pp. 245-247.

Mendonça, J.R.; Carvalho, A.M.; Mattos-Silva, L.A. \& Thomas, W.W. 1994. 45 anos de desmatamento no sul da Bahia. Projeto Mata Atlântica do Nordeste/CEPEC, Ilhéus, Bahia.

Menezes, C.M \& Pinto, G.C.P 1998. Poaceae Juss. In: Guedes, M.L.S. \& Orge, M.D.R. (eds.).
Checklist das espécies vasculares do Morro do Pai Inácio (Palmeiras) e Serra da Chapadinha (Lençóis), Chapada Diamantina, Bahia, Brasil. Universidade Federal da Bahia, Salvador. 68p.

MMA (Ministério do Meio Ambiente). 2008. Lista Oficial das Espécies da Flora Brasileira Ameaçadas de Extinção. http://www.mma.gov.br/ estruturas/ascom_boletins/_arquivos/83_ 19092008034949.pdf. Acesso em 10 out. 2008.

Mori, S.A.; Silva, L.A.M.; Lisboa, G. \& Coradin, L. 1989. Manual de manejo do herbário fanerogâmico. 2 ed. Centro de Pesquisas do Cacau, Ilhéus. 97p.

Oliveira, R.P. 2001. A tribo Olyreae (Poaceae: Bambusoideae) no estado da Bahia, Brasil. Dissertação de Mestrado. Universidade Estadual de Feira de Santana, Feira de Santana. 190p.

Oliveira, R.P. 2006. Estudos taxonômicos, filogenéticos e biossistemáticos em Raddia Bertol. (Poaceae - Bambusoideae-Olyreae), Tese de Doutorado. Universidade Estadual de Feira de Santana, Feira de Santana. 311p.

Oliveira, R.P. \& Clark, L.G. 2009. A tiny new Brazilian species of Diandrolyra (Poaceae: Bambusoideae: Olyreae), with notes on the systematics of the genus. Novon (Saint Louis) 19(2): 209-214.

Oliveira, R.P. \& Longhi-Wagner, H.M. 2001. In: Wanderley, M.G.L.; Shepherd, G.J. \& Giulietti, A.M. (orgs.). Flora fanerogâmica do estado de São Paulo. Volume I. Poaceae. Instituto de Botânica, São Paulo. 292p.

Oliveira, R.P. \& Longhi-Wagner, H.M. 2005. Olyra bahiensis (Poaceae, Olyreae): uma nova espécie para a mata atlântica do estado da Bahia, Brasil. Revista Brasileira de Botânica 28(4): 835-839.

Renvoize, S.A. 1984. The grasses of Bahia. Royal Botanic Gardens, Kew. 301p.

Renvoize, S.A. 1995. Gramineae. In: Stannard, B. (ed.). Flora of the Pico das Almas, Chapada Diamantina, Bahia, Brazil. Royal Botanic Gardens, Kew. Pp. 704-720.

Renvoize, S.A. 2003. Poaceae. In: Zappi, D.C.; Lucas, E.; Stannard, B.L.; Nic Lughadha, E.; Pirani, J.R.; Queiroz, L.P.; Atkins, S.; Hind, D.J.N.; Giulietti, A.M.; Harley, R.M. \& Carvalho, A.M. (eds.). 2003. Lista das plantas vasculares de Catolés, Chapada Diamantina, Bahia, Brasil. Boletim de Botânica da Universidade de São Paulo 21(2): 345-398.

Renvoize, S.A. \& Longhi-Wagner, H.M. 2008. Banco de dados de plantas do Nordeste. Disponível em: http://www.cnip.org.br/bdpn/ficha.php? 
cookieBD=cnip7\&taxon=9744. Acesso em: 10 outubro 2008.

Sánchez-Ken, J.G.; Clark, L.G.; Kellogg, E.A. \& Kay, E.E. 2007. Reinstatement and emendation of subfamily Micrairoideae (Poaceae). Systematic Botany 32: 71-80.

Schiller, A.; Oltrogge, K.; Triplett, J. \& Clark, L.G. 2006. The species of Chusquea subgenus Rettbergia of Brazil. http://www.eeob.iastate. edu/research/bamboo/keys/Rettbergia/ rettbergia.html. Acesso em: 10 outubro 2008.

SEI (Superintendência de Estudos Econômicos e Sociais da Bahia). 2007. Municípios em síntese. Disponível em: http://www.sei.ba.gov.br/ município/index_mun_mapa.php\#. Acesso em: 20 março 2007.

Sendulsky, T. 1995. Merostachys multiramea (Poaceae: Bambusoideae: Bambuseae) and similar species from Brazil. Novon 5(1): 76-96.

Sendulsky, T. 1997. Twelve new species of Merostachys (Poaceae: Bambusoideae: Bambuseae) from Brazil. Novon 7(3): 285-307.

Sendulsky, T. 2001a. Merostachys Spreng. In: Wanderley, M.G.L.; Shepherd, G.J. \& Giulietti, A.M. (orgs.). Flora fanerogâmica do estado de São Paulo. Volume I. Poaceae. Instituto de Botânica, São Paulo. 292p.

Sendulsky, T. 2001b. Merostachys Spreng. (Poaceae, Bambusoideae, Bambuseae): a new species from
Brazil and critical notes on "group speciosa". Kew Bulletin 56(3): 627-638.

Soderstrom, T. R. \& Calderón, C. E. 1974. Primitive forest grasses and evolution of the Bambusoideae. Biotropica 6(3): 141-153.

Soderstrom, T. R. \& Young, S.M. 1983. A guide to collecting bamboos. Annals of the Missouri Botanical Garden 70: 128-136.

Soderstrom, T. R.; Judziewicz, E.J.L. \& Clark, L.G. 1988. Distribution patterns in neotropical bamboos. In: Vanzolini,P.E. \& Heyer,W.R. (eds.). Proceedings of the neotropical biotic distribution pattern workshop. Rio de Janeiro, Brazil: Academia Brasileira de Ciências. Pp. 120-156.

Soderstrom, T. R. \& Zuloaga, F.O. 1989. A revision of the genus Olyra and new segregate genus Parodiolyra (Poaceae: Bambusoideae: Olyreae). Smithsonian Contributions to Botany 69: 1-79.

Thomas, W.W.; Carvalho, A.M.; Amorim, A.M.; Garrison, J.; Arbelaez, A.L. 1998. Plant endemism in two forests in southern Bahia, Brazil. Biodiversity and Conservation 7(3): 311-322.

Zhang, W. \& Clark, L.G. 2000. Phylogeny and classification of the Bambusoideae (Poaceae). In: Jacobs, S.W.L. \& Everett, J. (eds.) Grasses systematics and evolution. CSIRO, Melbourne. Pp. 35-42.

\section{LisTa DE EXCICATAS}

O número entre parêntesis corresponde ao número sequencial de cada táxon tratado no texto.

Amorim, A. M.: 4163 (1.1), 4354 (1.1), 6532 (1.1), 6558 (1.1), 6993 (4.1); Borges, R. A. X.: 282 (1.1), 311 (5.1), 357

(3.1); Fiaschi, P.: 2888 (1.1); Ferreira, F.M.: 1289 (1.1), 1306 (1.1), 1308 (5.1); Lopes, M. M. M.: 408 (1.1), 412

(3.1), 601 (1.1); Mota, A. C.: 50 (3.1), 52 (3.1), 53 (1.2), 54 (3.1), 55 (5.1), $58(1.1), 58(1.2), 62(3.1), 70(1.1), 82(1.4)$, 188 (1.1), 195 (1.2), 199 (2.1), 200 (5.1), 203 (3.1), 221 (1.2), 222 (1.3), 223 (1.1), 229 (4.1), 231 (2.1), 240 (1.4), 250 (2.1), 256 (1.3), 258 (1.4); Oliveira, R.P.: 1235 (3.1), 1238 (6.1), 1241 (1.1); Reginato, M.: 193 (1.1); Sant'Ana, S. C.: 1262 (1.1); Thomas, W.W.: $13756(1.1), 14210(1.1), 14231(1.1)$. 